\section{Pacific Northwest}

National Laboratory

Operated by Battelle for the

U.S. Department of Energy

\title{
Field Demonstration of a High-Efficiency Packaged Rooftop Air Conditioning Unit at Fort Gordon, Augusta, GA
}

\section{Final Report}

\author{
P.R. Armstrong \\ G.P. Sullivan \\ G.B. Parker
}

March 2006

Prepared for the U.S. Department of Energy

Office of Energy Efficiency and Renewable Energy

Building Technologies Program

Federal Energy Management Program

under Contract DE-AC05-76RL01830

and

U.S. Army Installation Management Agency

Southeast Region Office, SERO 


\title{
DISCLAIMER
}

This report was prepared as an account of work sponsored by an agency of the United States Government. Neither the United States Government nor any agency thereof, nor Battelle Memorial Institute, nor any of their employees, makes any warranty, express or implied, or assumes any legal liability or responsibility for the accuracy, completeness, or usefulness of any information, apparatus, product, or process disclosed, or represents that its use would not infringe privately owned rights. Reference herein to any specific commercial product, process, or service by trade name, trademark, manufacturer, or otherwise does not necessarily constitute or imply its endorsement, recommendation, or favoring by the United States Government or any agency thereof, or Battelle Memorial Institute. The views and opinions of authors expressed herein do not necessarily

state or reflect those of the United States Government or any agency thereof.

\author{
PACIFIC NORTHWEST NATIONAL LABORATORY \\ operated by \\ BATTELLE \\ for the \\ UNITED STATES DEPARTMENT OF ENERGY \\ under Contract DE-AC05-76RL01830
}




\title{
Field Demonstration of a High-Efficiency Packaged Rooftop Air Conditioning Unit at Fort Gordon, Augusta, GA
}

\section{Final Report}

\author{
P.R. Armstrong \\ G.P. Sullivan \\ G.B. Parker
}

March 2006

Prepared for the U.S. Department of Energy

Office of Energy Efficiency and Renewable Energy

Building Technologies Program

Federal Energy Management Program

under Contract DE-AC05-76RL01830

and

U.S. Army Installation Management Agency

Southeast Region Office, SERO

Pacific Northwest National Laboratory

Richland, Washington 99352 


\section{Executive Summary}

As part of a larger program targeting the market transformation of packaged rooftop air conditioning, five high-efficiency rooftop air conditioning products were selected in 2002 by the U.S. Department of Energy (DOE) under the Unitary Air Conditioner (UAC) Technology Procurement (http://www.pnl.gov/uac).

In February 2003, Fort Gordon in Augusta, Georgia was chosen as the demonstration site. With the goal of validating the field performance of one of the awarded products, a 10-ton high-efficiency packaged rooftop unit (RTU) manufactured by Global Energy Group ${ }^{1}$ (GEG) was installed at Fort Gordon in October 2003.

Power metering, air- and refrigerant-side instrumentation was installed on the GEG RTU and on a 4-year-old typical-efficiency 20 -ton RTU manufactured by AAON ${ }^{2}$. The GEG and AAON units were instrumented identically and operated May through July, 2005, to observe performance under a range of conditions.

Based on the data collected in this demonstration, the GEG equipment performed at least $8 \%$ better in stage 1 (single compressor running) cooling and at least $16 \%$ better in stage 2 (both compressors running) than the baseline AAON equipment. Performance comparisons are based on what we call application EER normalized to equivalent specific fan power $^{3}$. The full-load, specific-fan-power-normalized application EER at ARI standard rating conditions was10.5 Btu/Wh for the GEG and 9.0 Btu/Wh for the baseline machine.

With a cost premium of nearly $50 \%$, the life-cycle cost analysis ${ }^{4}$ shows that the GEG technology pays for itself--a positive net-present value (NPV)--only in climates and buildings with long cooling seasons. Table S.1 summarizes these findings for a hypothetical building with constant internal and solar gains based on bin analysis.

Table S.1 Summary of Life-Cycle Cost Analyses for Selected Locations

\begin{tabular}{|c|c|c|c|c|c|c|c|}
\hline \multirow[b]{2}{*}{ City } & \multicolumn{2}{|c|}{$\begin{array}{l}\text { Annual Load } \\
\text { FLEO }\end{array}$} & \multicolumn{2}{|c|}{ Baseline } & \multicolumn{2}{|c|}{ New Technology } & \multirow{2}{*}{$\begin{array}{c}\text { NPV } \\
\$\end{array}$} \\
\hline & kBtu & $\mathrm{H}$ & kWh & PV\$ & kWh & PV\$ & \\
\hline Atlanta, GA & 193168 & 1680 & 19011 & 18092 & 17439 & 16596 & -503 \\
\hline Augusta, GA & 329389 & 2864 & 31412 & 29894 & 29001 & 27599 & 296 \\
\hline Chicago, IL & 133243 & 1159 & 13389 & 12742 & 12269 & 11676 & -933 \\
\hline Denver, CO & 114730 & 998 & 11773 & 11204 & 10779 & 10258 & -1053 \\
\hline Phoenix, AZ & 226378 & 1969 & 26254 & 24985 & 22961 & 21851 & 1136 \\
\hline San Francisco, CA & 135851 & 1181 & 8916 & 8485 & 8428 & 8020 & -1534 \\
\hline Seattle, WA & 93685 & 815 & 6956 & 6620 & 6523 & 6208 & -1586 \\
\hline Baltimore, MD & 158491 & 1378 & 15718 & 14958 & 14408 & 13712 & -752 \\
\hline
\end{tabular}

The first column shows the annual cooling load of a hypothetical building with a 10-ton design load. The two columns headed Baseline show the electrical energy to operate a conventional RTU each year and the present value of that energy. The two columns headed New Technology show the electrical energy to operate the GEG RTU each year and the present value of that energy. The last column shows the net present value (NPV) for the new compared to the baseline technology. NPV accounts for differences in first cost and maintenance cost, as well as energy cost. A positive NPV indicates that the new technology is a better investment while a negative NPV indicates that the conventional technology is a better investment. Because

\footnotetext{
${ }^{1}$ GEG was acquired in August, 2005, by Cherokee Nations Industries.

Global Energy Group Inc., 5000 Legacy Drive, Suite 470, Plano, TX 75024

Phone: 972-943-6000, Fax: 972-403-7659, Web Site: http://www.gegsolutions.com

Inventor Series 1400 is not being produced anymore; a new model that eliminates one of the two water pumps and desuperheater fan is under development to begin production in mid or late 2006. The subcooler will be a water-to-refrigerant heat exchanger instead of an air-to-refrigerant heat exchanger.

${ }^{2}$ AAON, Inc., 2425 South Yukon Avenue, Tulsa, Oklahoma 74107

Phone: (918) 583-2266, Fax: (918) 583-6094, Web Site: http://www.aaonnet.com/

${ }^{3}$ Application EER is the energy efficiency ratio (Btu/Wh) measured in the field; specific fan power is the $\mathrm{kW}$ per rated ton required to operate the supply fan, which is usually substantially higher in applications than in the rating lab.

${ }^{4}$ Using $4 \%$ discount rate, $0.08 \$ / \mathrm{kWh}$, and 20-year analysis period (Fuller and Rushling 2005).
} 
of its higher first cost and slightly higher maintenance cost, the new technology is a better investment only for buildings and climates that result in a long cooling season, i.e., full-load equivalent operating hours (FLEOH) greater than about 1800 hours per year. As a rule, a flat load distribution (high FLEOH) favors more energy-efficient types of equipment and justifies the higher first cost.

Manufacture of this equipment on a larger scale can be expected to reduce costs to the point where it is more broadly cost-effective. The assumed 10-ton baseline and new-technology unit costs are $\$ 3824$ and $\$ 5525$ respectively. If the new technology cost is assumed to drop as sales increase to $\$ 4674$ for a 10 -ton unit (i.e. the original cost difference is halved), the life-cycle costs improve, as shown in Table S.2. With the hypothetical reduced first cost the GEG is attractive in applications with FLEOH > 1200 hours per year.

Table S.2 Life-Cycle Cost Comparison with Lower GEG Cost Assumed

\begin{tabular}{|c|c|c|c|c|c|c|c|}
\hline \multirow[b]{2}{*}{ City } & \multicolumn{2}{|c|}{$\begin{array}{c}\text { Annual Load } \\
\text { FLEO }\end{array}$} & \multicolumn{2}{|c|}{ Baseline } & \multicolumn{2}{|c|}{ New Technology } & \multirow{2}{*}{$\begin{array}{c}\text { NPV } \\
\$\end{array}$} \\
\hline & kBtu & $\mathrm{H}$ & kWh & PV\$ & kWh & PV\$ & \\
\hline Atlanta, GA & 193168 & 1680 & 19011 & 18092 & 17439 & 16596 & 348 \\
\hline Augusta, GA & 329389 & 2864 & 31412 & 29894 & 29001 & 27599 & 1147 \\
\hline Chicago, IL & 133243 & 1159 & 13389 & 12742 & 12269 & 11676 & -82 \\
\hline Denver, CO & 114730 & 998 & 11773 & 11204 & 10779 & 10258 & -202 \\
\hline Phoenix, AZ & 226378 & 1969 & 26254 & 24985 & 22961 & 21851 & 1986 \\
\hline San Francisco, CA & 135851 & 1181 & 8916 & 8485 & 8428 & 8020 & -683 \\
\hline Seattle, WA & 93685 & 815 & 6956 & 6620 & 6523 & 6208 & -736 \\
\hline Baltimore, MD & 158491 & 1378 & 15718 & 14958 & 14408 & 13712 & 98 \\
\hline
\end{tabular}

There is a retrofit version of the technology that may be LCC-effective in many applications. In both implementations, however, the user must make a commitment to periodically checking the evaporative cooling subsystem which is mechanically similar to a swamp cooler.

\section{Acknowledgments}

This report is the result of several organizations working to achieve a common goal of researching, evaluating and promoting energy efficiency. The work was jointly supported by the Department of Energy Building Technologies and Federal Energy Management Programs and by the U.S. Army Installation Management Agency.

The authors wish to acknowledge the contribution and valuable assistance provided by the staff at Fort Gordon. Specifically, we would like to thank the base energy manager Glenn Stubblefield and demonstration facility manager Lawrence Jackson; we greatly appreciate their patience and willingness to help in our demonstration of this air conditioning equipment.

Integral to the success of this demonstration was the coordination and support of the participating equipment manufacturer - the Global Energy Group. In particular, we would like to recognize the efforts of Rich Weisbrodt for his assistance in system diagnosis and set-up.

Appreciation is extended to the PNNL ${ }^{5}$ team of Doug Dixon, Marc Ledbetter, Brad Holloman, Dave Winiarski, Jeff McCollough, and Sue Arey for the conscientious, team-oriented, and high quality assistance they brought to this project.

We wish to recognize Steve Jackson, Energy Manager, U.S. Army Installation Management Agency, Southeastern Region for his vision, commitment and support in helping create and fund this project.

Finally, the guidance and support of Rick Orrison, Technology Development Manager, Emerging Technology Program, Department of Energy-Building Technology, was instrumental to completion of this work.

\footnotetext{
${ }^{5}$ Pacific Northwest National Laboratory operated by Battelle for the United States Department of Energy under Contract DE-ACO5-76RL0183O
} 


\section{Contents}

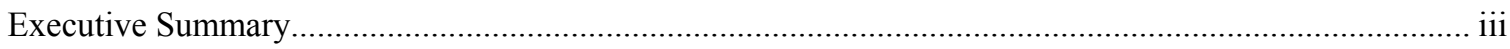

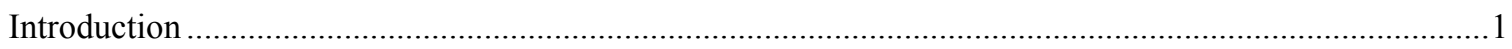

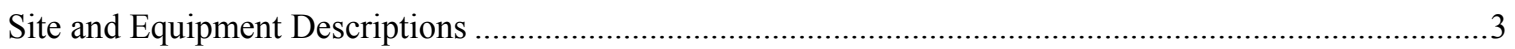

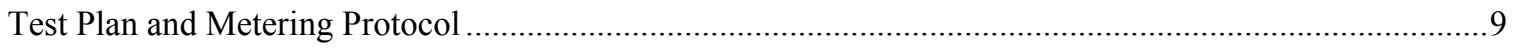

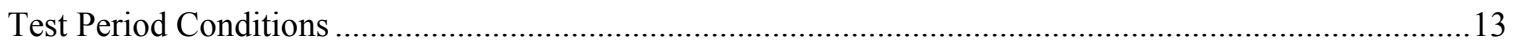

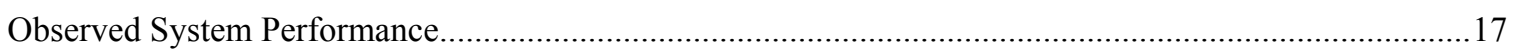

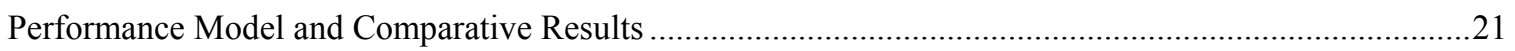

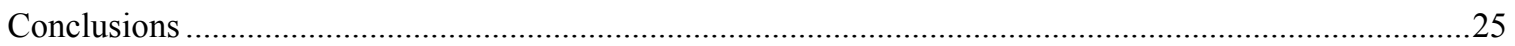

Appendix A: Refrigerant-Side Capacity Measurement ........................................................................29

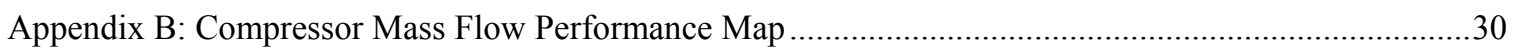

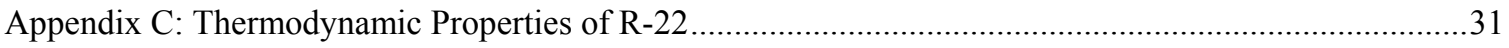

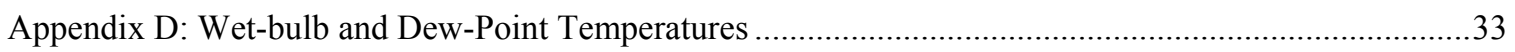

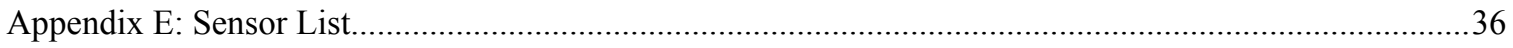

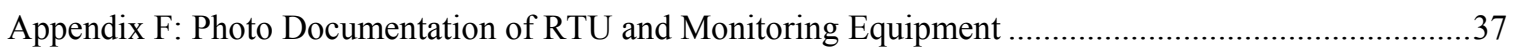

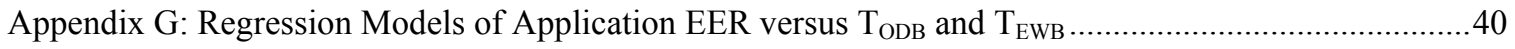

Appendix H: ARI Standard 340/360 Rating Conditions .............................................................................

Appendix I: Energy and Life-Cycle Cost by the UAC Cost Estimator .......................................................4

Appendix J: Issues in Measurement of Package A/C Field Performance ....................................................47

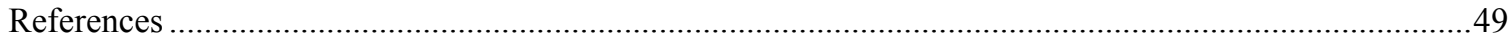




\section{Field Demonstration of a High-Efficiency Packaged Rooftop Air Conditioning Unit at Fort Gordon, Augusta, GA}

\section{Introduction}

As part of a larger program targeting the market transformation of packaged rooftop air conditioning, five high-efficiency rooftop air conditioning products were selected in 2002 by the U.S. Department of Energy (DOE) under the Unitary Air Conditioner Technology Procurement http://www.pnl.gov/uac/. After selecting the winning products based on their lowest life-cycle cost (LCC), the Pacific Northwest National Laboratory (PNNL) awarded basic ordering agreements (BOAs), specifying prices, warranties and other terms, for several high-efficiency rooftop air conditioners offered by Lennox Industries Inc. and the Global Energy Group ${ }^{6}$ (GEG). Non-federal buyers, including state and local government agencies, institutional facilities, and private companies, could order the winning air conditioners through the BOA administered by PNNL, and Federal buyers could order the units through Defense Logistics Agency's (DLA) Maintenance Repair and Operation (MRO) prime vendor program. The goal of this program was to accelerate the market introduction of high-efficiency, cost-effective rooftop air conditioners.

In February 2003, Fort Gordon was chosen as the site for the demonstration of a high-efficiency packaged rooftop unit (RTU). With the goal of validating the field performance and operation of one of the awarded products, a 10-ton RTU manufactured by GEG was installed at Fort Gordon in October 2003. The equipment, procedures and analyses used to measure performance, and the estimated LCC savings based on performance measured at the test site, are reported here.

\footnotetext{
${ }^{6}$ GEG was purchased in August, 2005, by Cherokee Nations Industries. Global Energy Group Inc., 5000 Legacy Drive, Suite 470, Plano, TX 75024

Phone: 972-943-6000, Fax: 972-403-7659, Web Site: http://www.gegsolutions.com
} 


\section{Site and Equipment Descriptions}

Located a few miles southwest of the city of Augusta, Georgia, Fort Gordon is one of the largest communications-electronics facilities in the world. The U.S. Army Signal Center and Fort Gordon, "The Home of the Signal Corps," trains more soldiers than any other branch training center of the United States Army. The Reserve Components Support Division provides year-round training for more than 60,000 reservists, as well as Army and Navy Reserve Officer Training Corps students. The Fort encompasses 56,000 acres, and has a work force of over 4,600 civilians and more than 12,000 soldiers. Fort Gordon was chosen for its climate, its pro-active stance on energy efficiency, and willingness to allow access and provide support for the installation of metering and communications equipment.

To initiate the demonstration, a survey of candidate buildings was performed at Fort Gordon. As part of the selection criteria, data were gathered on site buildings by function, construction, age, air conditioning type, and access. Also, it was necessary to identify buildings that had both a candidate RTU for replacement and another co-located RTU (serving a similar zone) to function as a baseline, or typicalefficiency, RTU. This survey resulted in a number of candidate buildings from which Building 18402, the Fort Gordon Club complex, was chosen. The Fort Gordon Club is a one-story structure, the 8,000-sf south wing of which contains kitchen and dining facilities and the 7,200-sf north wing of which serves as an assembly hall, social events, and night club facility. The building is open 7:00 am to 7:00 pm weekdays with variable hours for evenings and weekends. The Fort Gordon Club has five RTUs of various ages and vendors ranging from 7.5 to 25 tons. Figures 1 and 2 show the Fort Gordon Club and its roof-top HVAC equipment as found on the initial site visit.

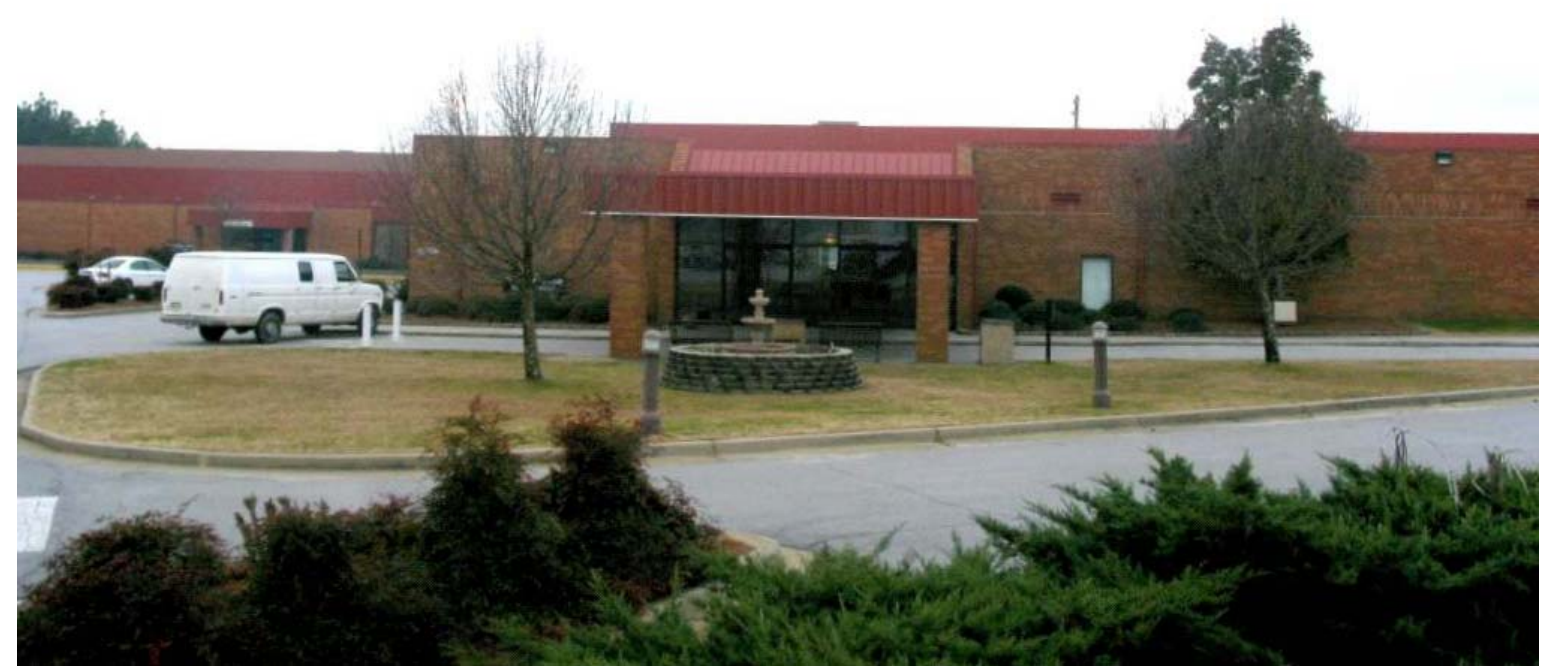

Figure 1. Building 18402 the Fort Gordon Club Viewed from the Northwest. 


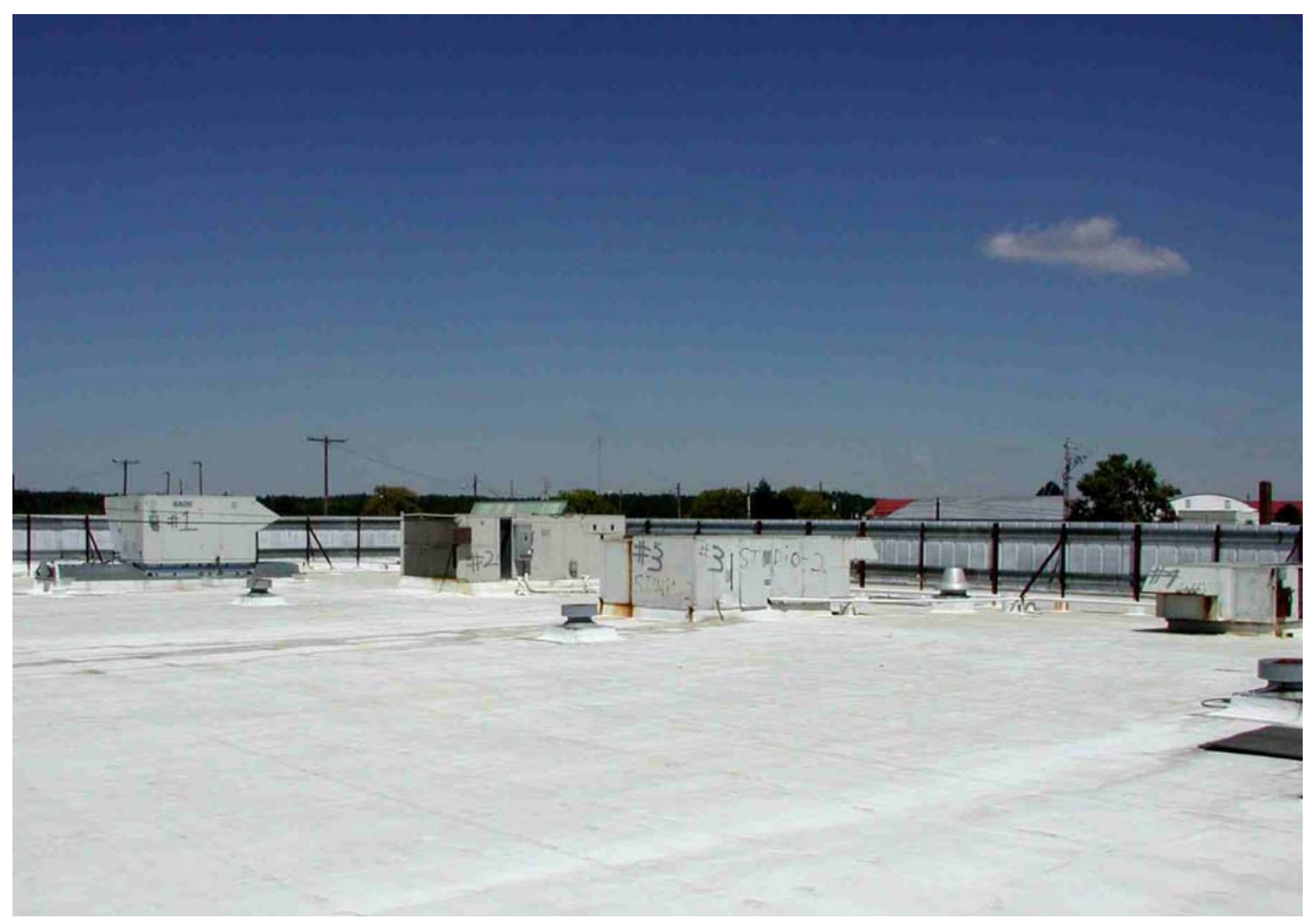

Figure 2. Rooftop View from the South of the Fort Gordon Club’s North Wing.

A key criterion for building selection was the presence of both a candidate RTU for replacement and a candidate RTU to serve as a control or baseline function. The Fort Gordon Club complex offered both of these. The candidate replacement RTU, pictured in Figure 3, was a J. Zink RTG-823. This unit was installed new in 1988.

Shown in Figure 4 is the baseline unit, an AAON RK Series 20-ton RTU. This unit was installed new in 2001. The AAON RTU serves an adjacent zone to the J. Zink RTU in the Fort Gordon Club complex. While the AAON RTU is larger than the candidate replacement RTU, it is a good match in terms of performance analysis. Both units have two stages of cooling provided by two identical compressors. The compressors used in both machines are of the same type: hermetic scroll compressors. These similarities are important to achieving the program's objective of making a field performance comparison. 


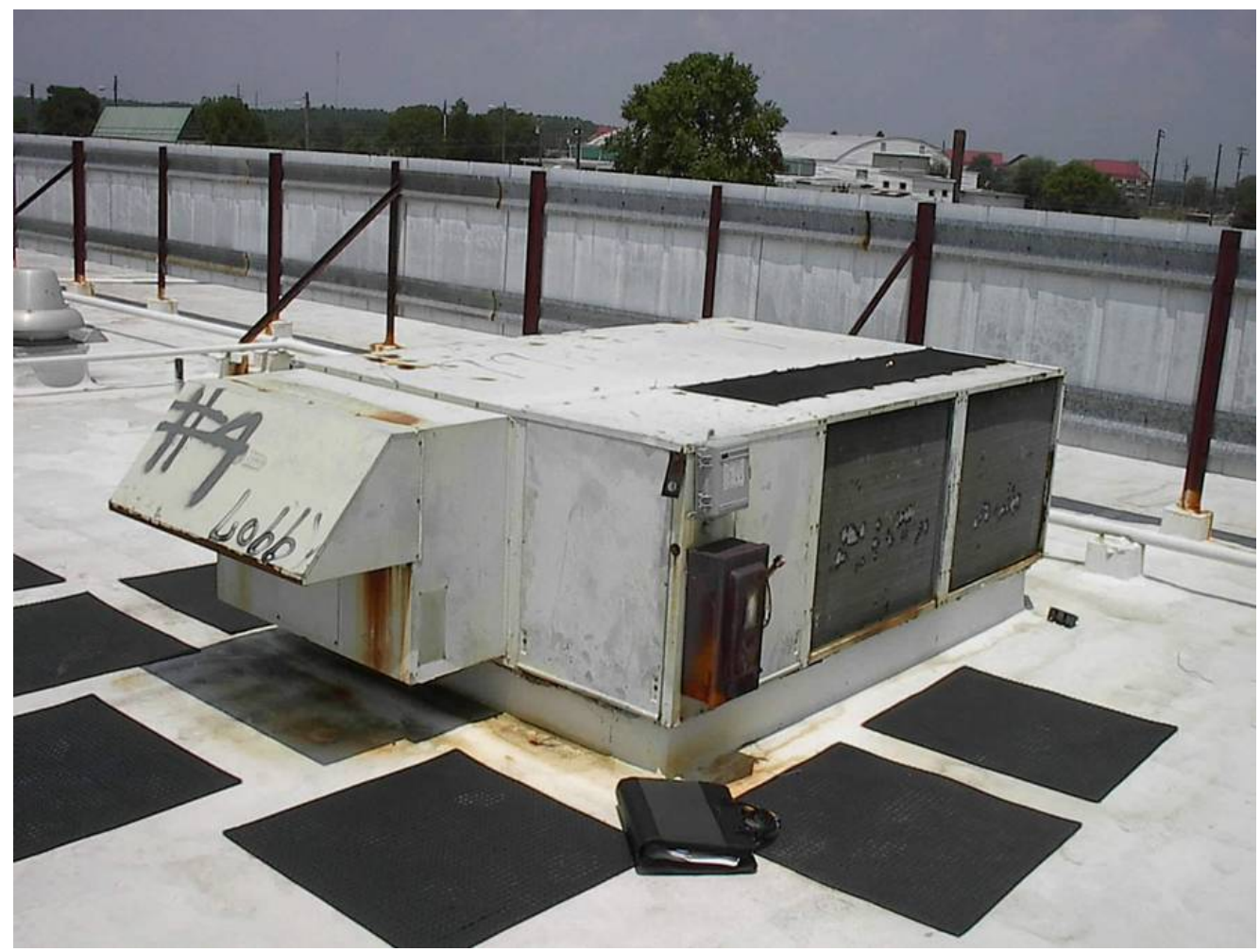

Figure 3. Fort Gordon RTU Replaced as Part of Demonstration

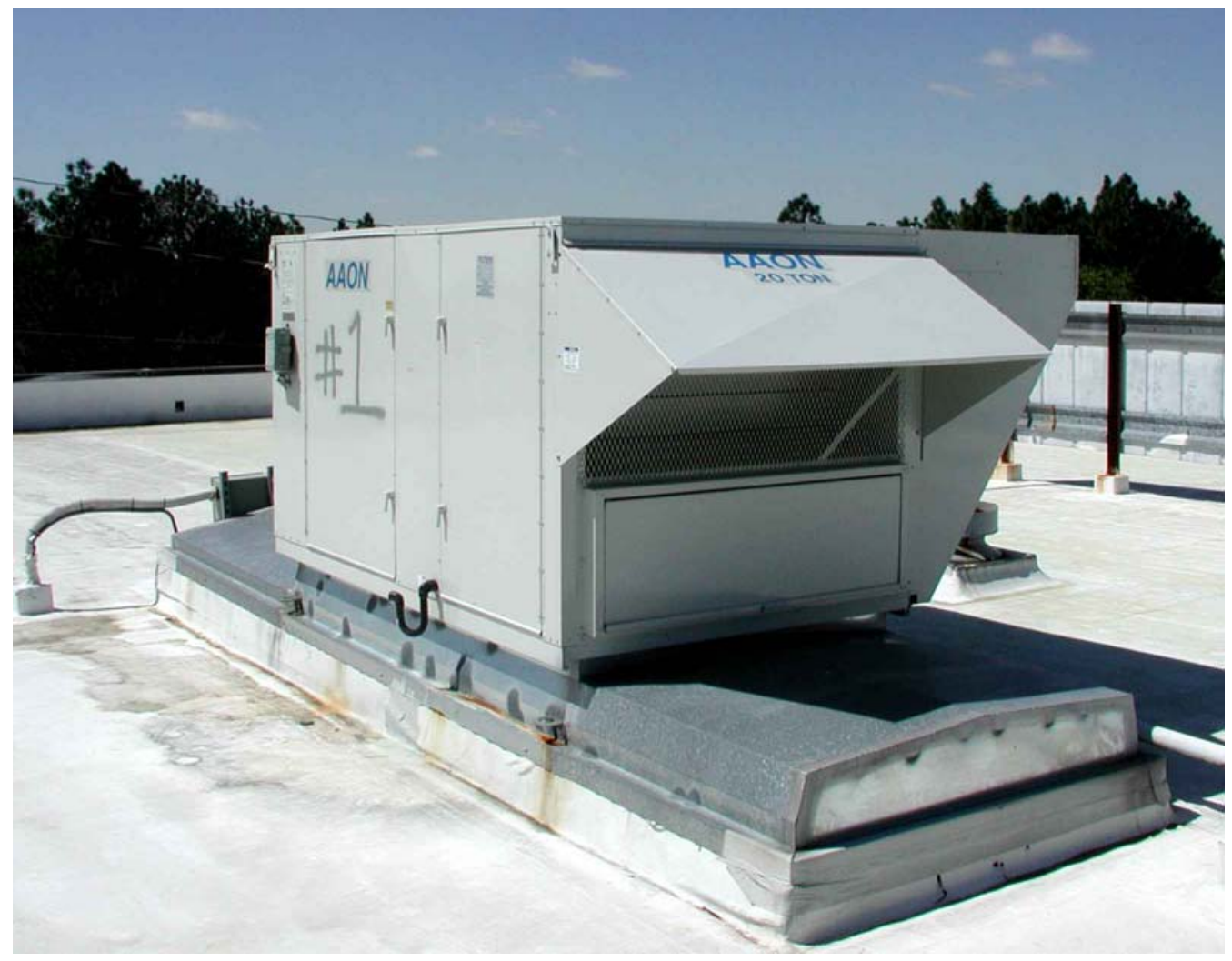

Figure 4. Fort Gordon AAON Baseline RTU 
Figure 5 presents the high-efficiency GEG Inventor 1400 Series RTU. This RTU differs from a conventional dry-condenser package direct expansion (DX) air-conditioner in its use of discrete desuperheating and subcooling coils and in its use of evaporative cooling to remove heat from these coils. The components are laid out, from left to right, as follows: outdoor air intake, controls access panel, filter and sump access door, supply fan door with furnace (louvered door) below, EER+ discharge hood with compressor access door below, condenser coils in V-configuration with top discharge.

Figure 6 shows the evaporative media over which condensate is passed to provide the cooling effect for the desuperheating and subcooling coils. These coils and the evaporative cooling hardware are referred to, collectively, as the EER+ technology.

Table 1 presents the relevant nameplate and performance data of the candidate RTUs. The AirConditioning and Refrigeration Institute (ARI) rated energy efficiency ratio (EER) values listed are experimentally derived in a laboratory setting under conditions specified by the ARI test procedure (ARI 2000). Once derived, these values are then reported to ARI for listing in the ARI guide (ARI 2005). The ARI EER is very useful in equipment comparisons; however, like EPA MPG ${ }^{7}$ ratings, the field performance, or what we call "application EER," is generally found to be lower than the ARI EER rating.

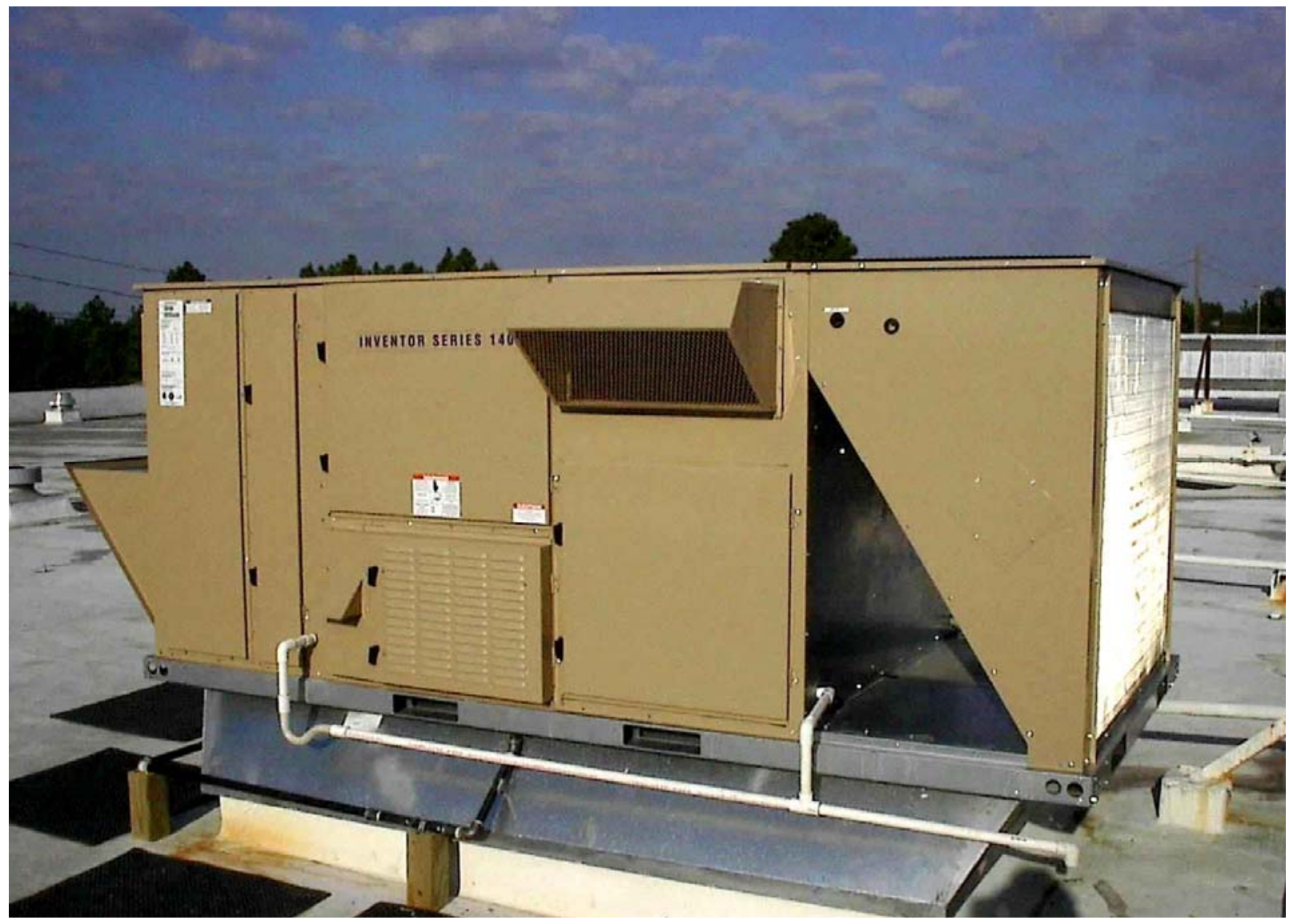

Figure 5. Fort Gordon GEG Inventor 1400 Series High-Efficiency RTU

\footnotetext{
${ }^{7}$ Automobile fuel use ratings expressed in miles-per-gallon (MPG) using Environmental Protection Agency (EPA) laboratory-simulated city and laboratory-simulated highway driving test protocols.
} 


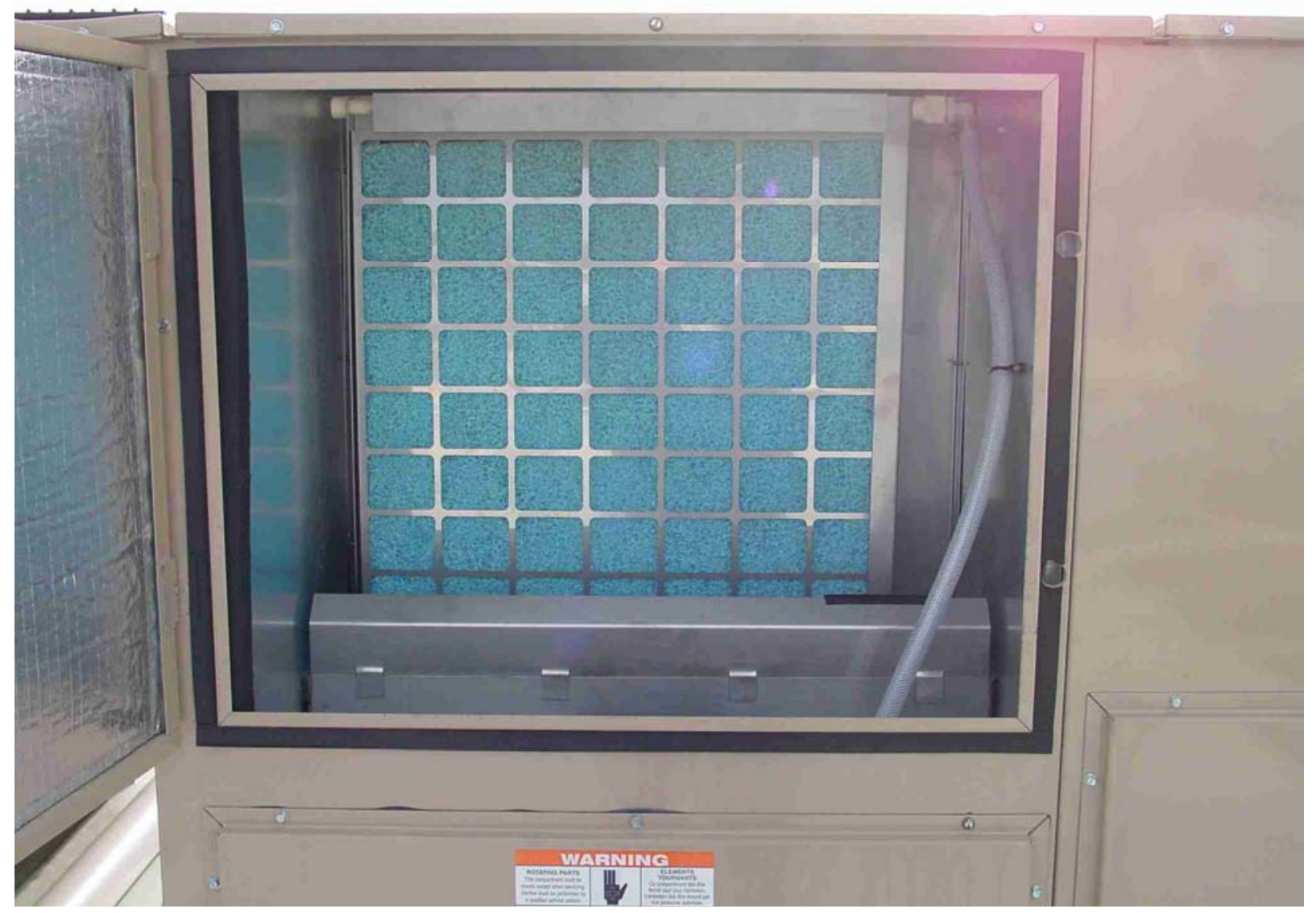

Figure 6. GEG Inventor 1400 Series Evaporative Media

Table 1. Nameplate and Performance Data for Candidate RTUs

\begin{tabular}{|l|c|c|c|}
\hline $\begin{array}{c}\text { Equipment } \\
\text { Manufacturer/Model }\end{array}$ & $\begin{array}{c}\text { Nominal } \\
\text { Size }\end{array}$ & $\begin{array}{c}\text { Approximate date of } \\
\text { Manufacture }\end{array}$ & $\begin{array}{c}\text { ARI Rated Energy } \\
\text { Efficiency Ratio (EER) }\end{array}$ \\
\hline J. Zink / RTG-823 & 7 tons & 1988 & $8^{\text {a }}$ \\
\hline AAON / RK Series & 20 tons & 2001 & 11.0 \\
\hline GEG / 1400 Inventor Series & 10 tons & 2003 & 13.4 \\
\hline \multicolumn{4}{|l}{ a The value listed is estimated based on general historic trends; an actual rating was not available } \\
\hline
\end{tabular}

The GEG and AAON units were initially instrumented in October 2003, but sufficient data for RTU performance analysis ware not collected until May 2004. At that time, problems were encountered measuring capacity on the air-side of both units. Sensor changes and one-time measurements were made in the summer of 2004 in attempts to diagnose the air-side instrumentation. Continuing problems led to the decision to supplement the air-side measurements with refrigerant-side capacity instrumentation.

Refrigerant-side capacity instrumentation, a more expensive and more accurate technique, was added to stage-1 cooling in October, 2004 and to stage-2 cooling in May 2005. Again, both the GEG and baseline AAON RTUs received the same instrumentation. Monitoring continued through July, 2005 to observe performance under a range of load and weather conditions. 
This report documents the metering protocol, the instrumentation, the refrigerant-side and psychrometric calculations and the regression analysis used to derive a model of performance in terms of indoor and outdoor thermal conditions. Additionally, the report presents the LCC analysis used to assess the energy and financial benefits that would accrue to a user of the GEG technology in a given building and climate. 


\section{Test Plan and Metering Protocol}

The project scope was established in early 2003 by selecting a site with the specific package units to be monitored and by developing a monitoring protocol appropriate to the site, the monitored equipment and the analysis objectives.

\section{RTU Selection}

The side-by-side test was planned so that the observed performance for the conventional and advanced technologies would be based on similar operating conditions. After the selection of the Fort Gordon Club as the demonstration site, monitoring of the five candidate RTUs was initiated and the one-minute-average electrical loads of each unit were recorded for a two-month period from May through June 2003. These readings and the resulting use patterns were examined to select two units with similar duty fraction. The end-use metering data logger used for this purpose, a Synergistic Model C180E, is shown in Figure 7. The logger measures active and reactive power of one-phase, three-phase delta, or three-phase wye circuits using appropriately sized instrument-grade current transformers and potential transformers to accommodate a wide range of loads from less than one to thousands of $\mathrm{kW}$. In this case, five three-phase delta circuits were monitored.

The data collected from the logger are plotted as normalized cumulative demand distributions in Figure 8 . On this plot, the vertical axis represents the 1-minute average load $(\mathrm{kW})$ as a fraction of maximum load observed during May-June 2003. The horizontal axis represents the fraction of time when the load is below a given fraction of the peak load. Each curve says something about the load factor of the zone served and provides an indication of whether the unit may be significantly oversized or undersized. From the plot, RTUs 2 and 5 appear to be oversized with RTU 2 running only $25 \%$ of the time in the May-June time frame. On the other hand, RTU 4 appears to be significantly undersized because it is running continuously. The sizing of RTU 1 and RTU 3 appear to be within acceptable limits. Nominal capacity and maximum observed electrical loads of the five units are summarized, along with basic nameplate data, in Table 2.

Because RTUs 2 and 5 have low frequency of operation neither was considered a good candidate for upgrade or to serve as the baseline unit. Both RTU 3 and RTU 4 were considered good candidates for replacement because they were 15 years old. The final choice was largely determined by available size of the GEG RTU; a 10-Ton unit appropriate for replacing the currently undersized 7-ton RTU 4 was available for immediate shipment. Also evident in the data was that RTU 1 is probably well sized for its application and, being relatively new (installed 2001), would serve well as the baseline for performance comparisons. Both units (RTU 1 AAON RK Series unit and RTU 4's replacement - the GEG unit) have similar staging with single-speed supply and condenser fans and two equal sized refrigeration circuits and compressors. In summary, because (at time of replacement) RTU 1 was 2 years old and RTU 4 was 15 years old it was clear that RTU 1 would better represent current "typical-efficiency" technology and RTU 4, perhaps nearing the end of its service life, was the logical unit to be replaced. 


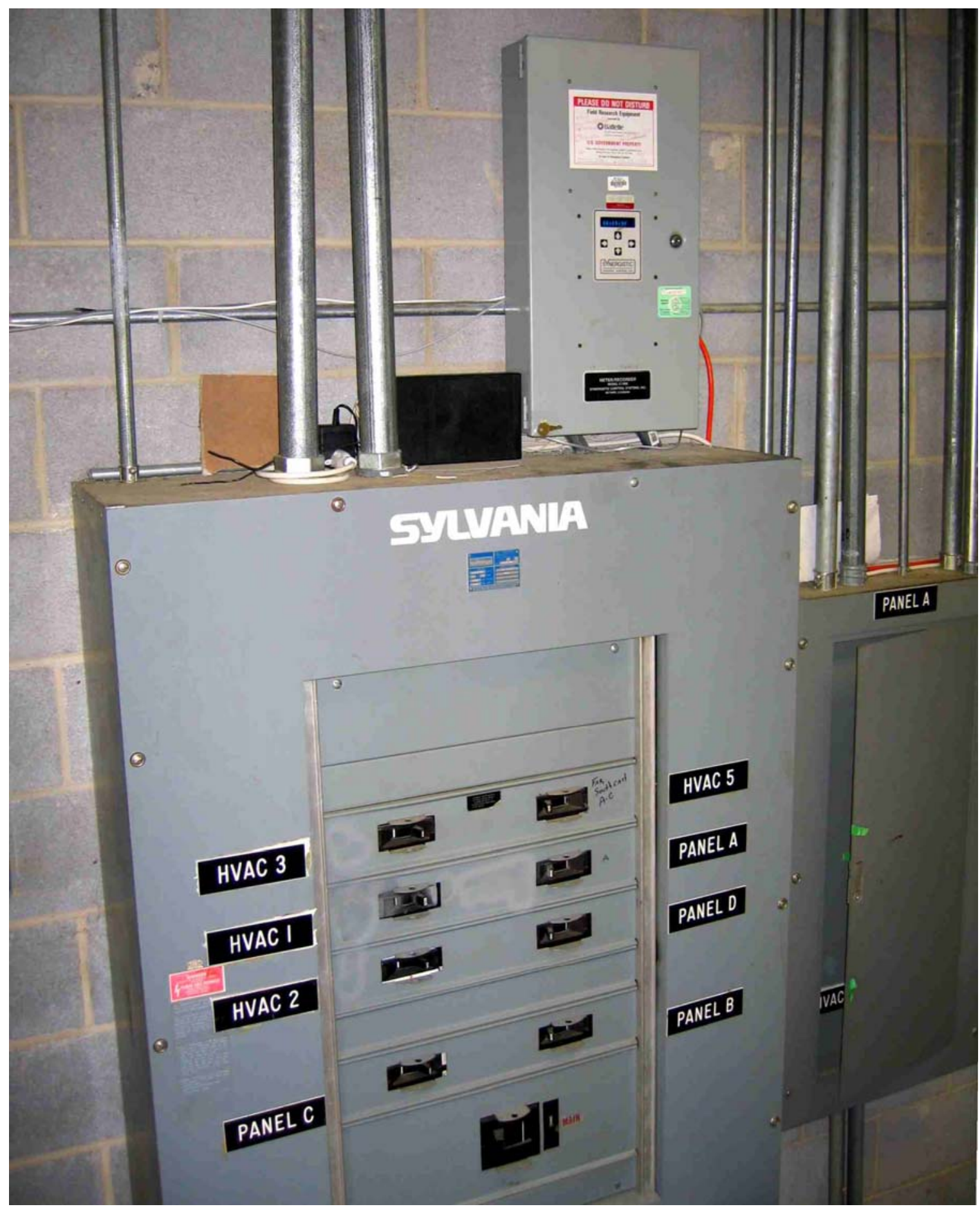

Figure 7. C180 Data Logger (upper right in photo) for Monitoring Electrical Loads 


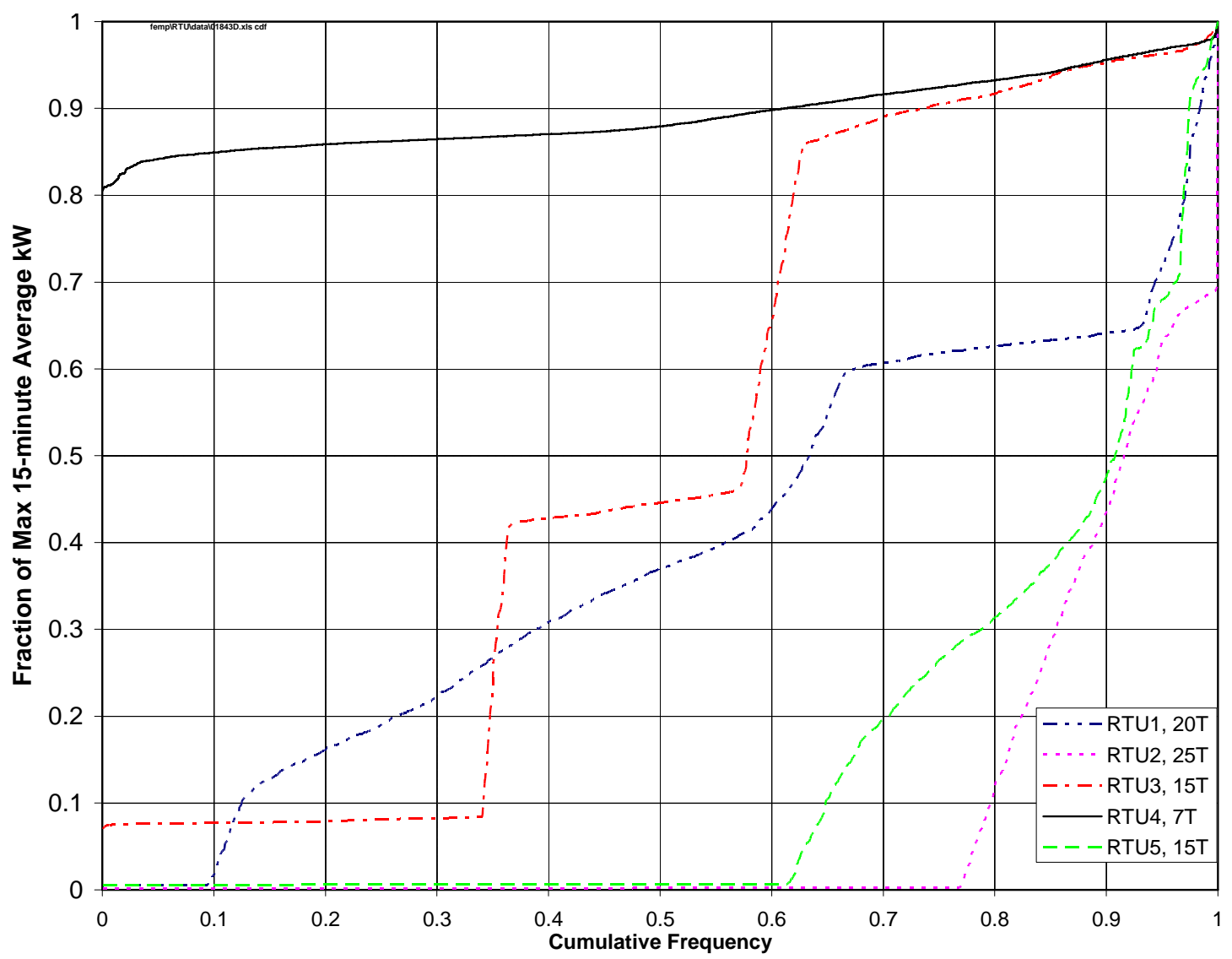

Figure 8. Cumulative distribution of normalized electrical load during May-June 2003. RTU 1 is the AAON 20-ton unit (dash-dot-dot). RTU 4 is the John Zink 7-ton unit (solid line) that was replaced in this project by the high-efficiency 10-ton unit.

Table 2. Electrical Load Summary Based on 15-Minute Average kW Data

\begin{tabular}{|l|c|l|c|c|c|c|}
\hline $\begin{array}{l}\text { RTU } \\
\text { Number }\end{array}$ & RTU Make & RTU Model & $\begin{array}{l}\text { Size } \\
\text { (tons) }\end{array}$ & $\begin{array}{l}\text { Maximum } \\
\text { Load (kW) }\end{array}$ & $\begin{array}{l}\text { Average } \\
\text { Load (kW) }\end{array}$ & $\begin{array}{l}\text { Duty } \\
\text { Fraction }\end{array}$ \\
\hline RTU 1 & AAON & RK-20-2-E0-222:CBOE & 20 & 23.82 & 9.20 & 0.39 \\
\hline RTU 2 & J. Zink & RTG-300 & 25 & 20.12 & 1.84 & 0.09 \\
\hline RTU 3 & J. Zink & RTG-153 & 15 & 12.86 & 6.50 & 0.51 \\
\hline RTU 4 & J. Zink & RTG-823 & 7 & 5.66 & 5.05 & 0.89 \\
\hline RTU 5 & AAON & RK-15-2-E0-322:CBOE & 15 & 15.79 & 2.36 & 0.16 \\
\hline
\end{tabular}

\section{Metering Protocol}

Proper selection of cooling equipment can only be achieved with complete and reliable information of seasonal loads, equipment performance, first cost, maintenance cost, and energy costs. Equipment performance information is needed for each candidate RTU to select the most cost-effective model for a given application. As one gage of performance, RTU manufacturers provide capacity and input power as a function of conditions based on the ARI laboratory test procedure previously mentioned. To be consistent, we have used a monitoring protocol that approximates such a laboratory test in the field.

For this demonstration, monitored conditions include barometric pressure and outdoor air temperature. Mixed-air temperature and relative humidity were measured at each of the two units. Power (three-phase 120/208V) was measured by the C180 data logger mentioned earlier. In addition, the total (latent plus sensible) cooling capacity of each unit was measured in two ways, refrigerant-side and air-side. 
Refrigerant-side capacity is the product of refrigerant mass flow rate and enthalpy change from the liquid line to the suction vapor line, as outlined in Appendix A. Mass flow rate is inferred from the ARI compressor performance map by measuring suction temperature and pressure and discharge pressure, as explained in Appendix B. The refrigerant properties are evaluated by the subroutines listed in Appendix C. The measurements and calculations were performed separately for each of two compressors (stage- 1 and stage-2) in each of the two monitored units.

Air-side capacity is the product of dry air mass flow rate and enthalpy difference across the coil per unit dry air mass. Moist air enthalpy is a function of temperature, relative humidity and barometric pressure, as outlined in Appendix D. Air flow is computed from a one-time measurement (traverse across the coil face) and a correction factor based on a fan inlet velocity factor. Nominal fan inlet velocity is given by the Bernoulli equation, $\Delta P=\rho V^{2}$, and density, $\rho$, is computed from supply air temperature, pressure and relative humidity (RH), as described in Appendix D. The sensors used to measure each variable required to execute the performance and conditions calculations outlined in Appendices A-D are documented in Appendix E.

The input power and total capacity for stage- 1 and stage- 2 operation of each RTU may be expressed as a function of operating conditions. The conditions of importance are mixed-air temperature and humidity, outdoor dry-bulb temperature, and supply air flow rate. If the supply air flow rate is constant, the machine's performance can be expressed in terms of two variables: outdoor dry-bulb and entering wet-bulb temperature. 


\section{Test Period Conditions}

The GEG RTU operated in stage-1 cooling mode (one of two 5-ton compressors operating) for 205.3 hours between June 9 and July 9, 2005. The distribution of run time is shown on a log-linear plot in Figure 9. Because the data was logged every minute, it is possible to determine start and stop times to the nearest minute. Records with less than a full minute of operation have been discarded. The actual run time is therefore, on average, about 1 minute greater ${ }^{8}$ than the run time recorded in any given bin. There were about 1,350 cycles of 10 minutes or less duration representing 90 hours of operation. There were about 290 cycles of greater than 10 minutes duration representing 115 hours of operation. There were about 140 cycles of 1- to 10-minute duration representing 7.9 hours of operation in stage-2 cooling mode.

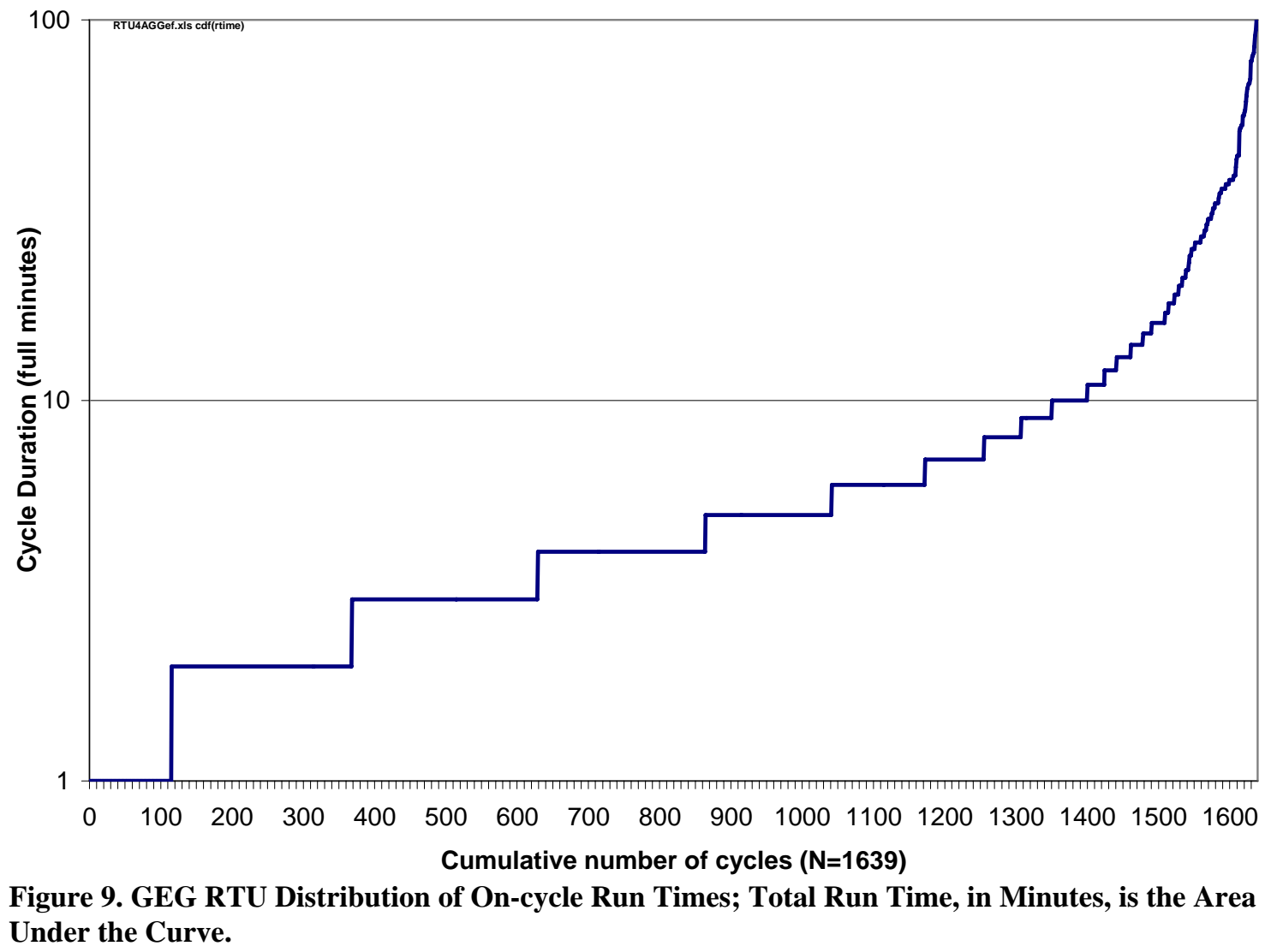

Conditions during the study period are indicated by the joint distribution of outdoor dry-bulb temperature $\left(\mathrm{T}_{\mathrm{ODB}}\right)$, entering wet-bulb temperature ( $\mathrm{T}_{\mathrm{EWB}}$, aka mixed-air wet-bulb temperature), and on-cycle duration, as shown in Figure 10. Each bubble represents a single on-cycle and the bubble area is proportional to the run time ( 2 to 130 minutes). From the plot we see stage- 1 cycle times generally increasing with both $\mathrm{T}_{\mathrm{ODB}}$ and $\mathrm{T}_{\mathrm{EWB}}$, as indicated by the increase in bubble area as we move from the lower left to the upper right quadrant of the plot. Also note that stage- 2 cycles follow the same trend and occur very rarely at low $\mathrm{T}_{\mathrm{ODB}}$ and $\mathrm{T}_{\mathrm{EWB}}$, as expected.

\footnotetext{
${ }^{8}$ To account for partial minutes and the beginning and end of each cycle, each 30 seconds average duration.
} 


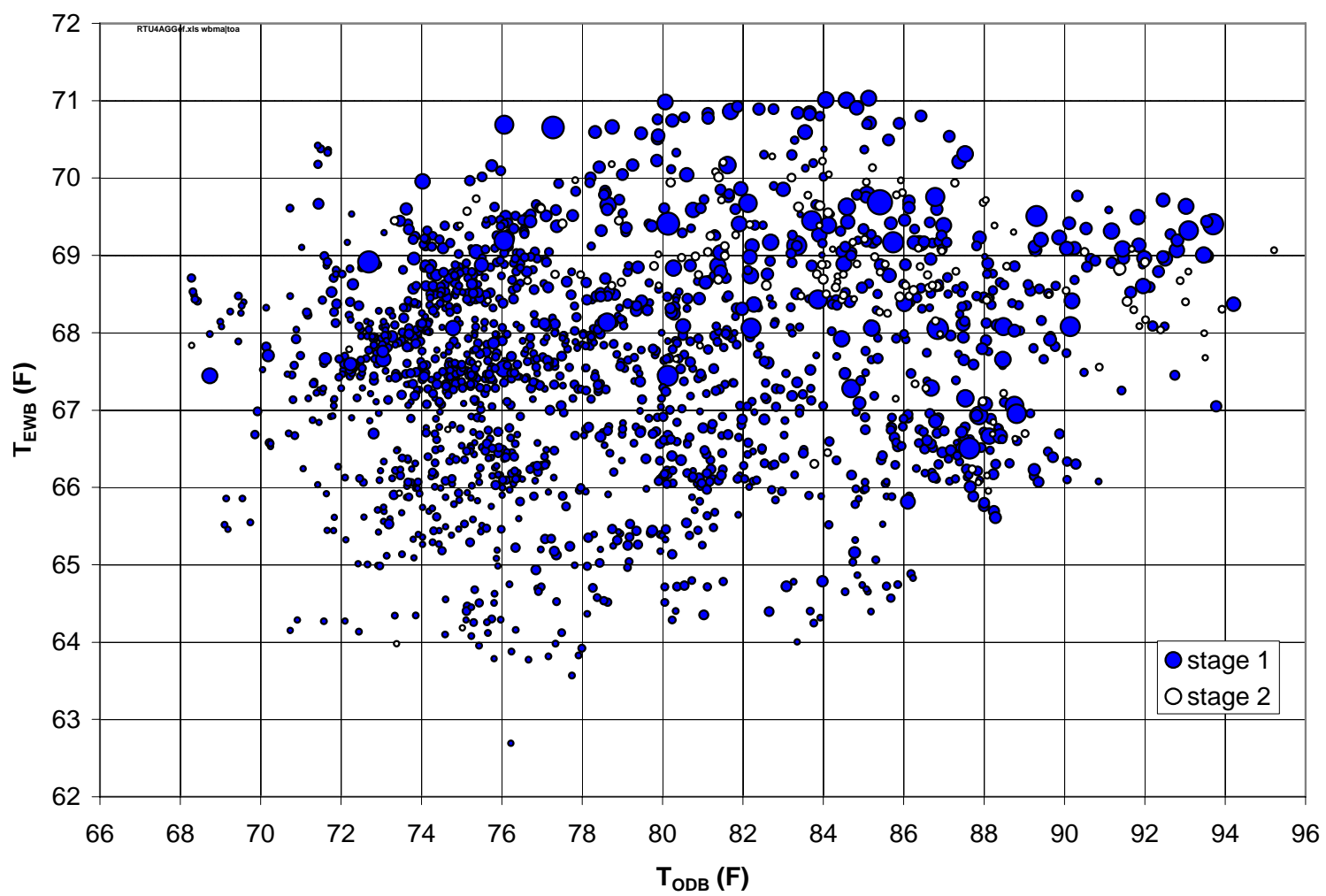

Figure 10. Joint Distribution of Entering Wet-Bulb and Outdoor Temperatures During GEG RTU Operation; Bubble Size is Proportional to On-Cycle Duration.

The joint distribution of capacity (measured in Btu/h) and input power (measured in $\mathrm{kW}$ ) is shown in Figure 11. Each bubble represents an on-cycle and again, the bubble area is proportional to the run time ( 2 to 100 minutes). Input power $(\mathrm{kW})$ was measured directly ${ }^{9}$ and capacity $(\mathrm{Btu} / \mathrm{h})$ was calculated from refrigerant-side measurements as described above and, more completely, in Appendix A. Stage-1 and stage-2 operating conditions form two distinct clusters of points as expected. The ranges of power and capacity within each cluster are a modest $(<10 \%)$ fraction of the mean. However, we will show that these variations are systematic and well-correlated, in the expected ways, with entering air and outdoor temperatures.

\footnotetext{
${ }^{9}$ A small bias in power measurement caused by line losses in the approximately 100 feet of 6-gage feed wiring, estimated by $\mathrm{I}^{2} \mathrm{R}$ calculation and verified from one-time measurement at the RTU disconnect, amounted to about $1 \%$ in stage- 2 cooling mode and less than $1 \%$ in stage- 1 cooling mode. This small effect was ignored because both units are affected similarly.
} 


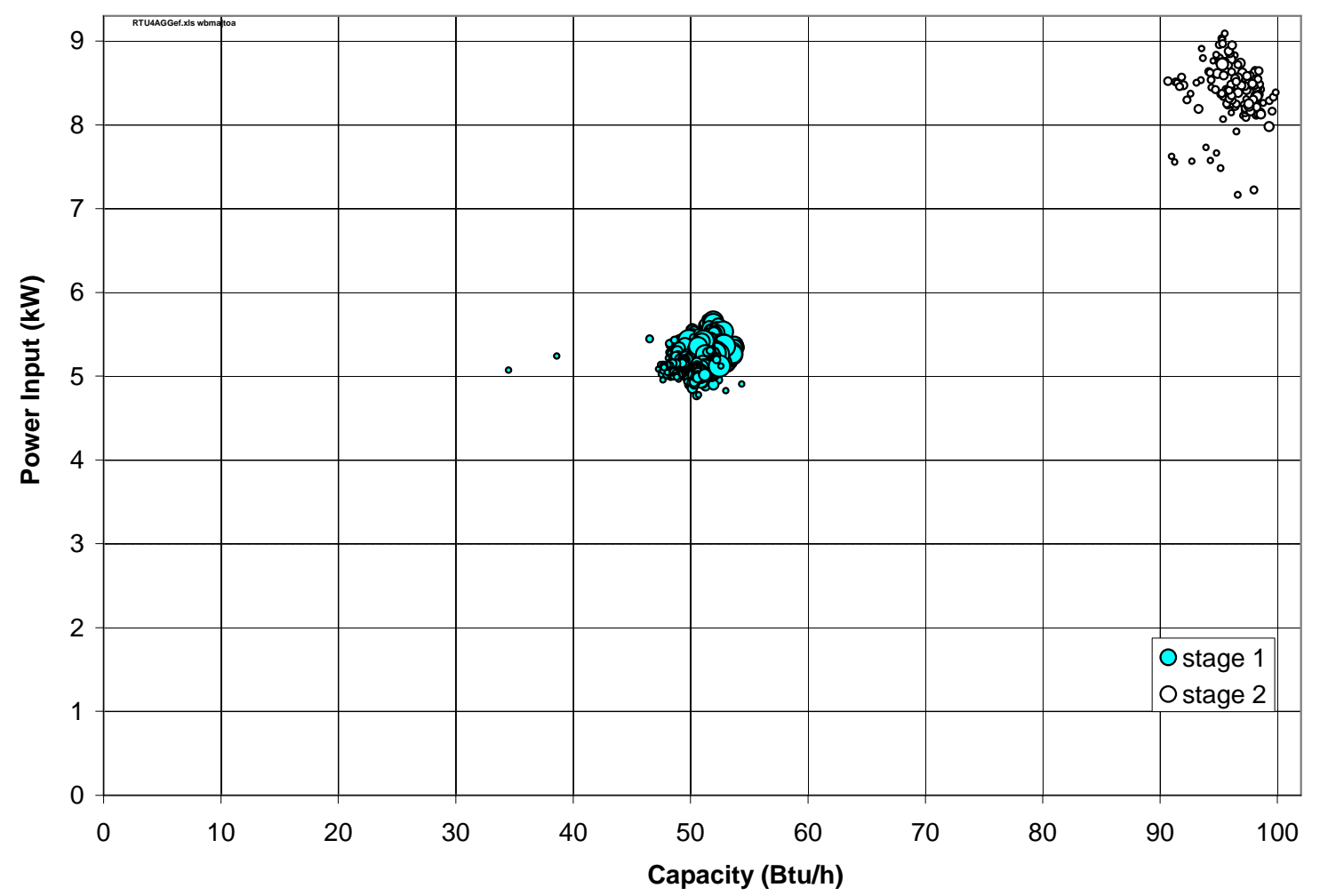

Figure 11. Joint Distribution of GEG RTU Power and Capacity; Bubble size is Proportional to OnCycle Duration. 


\section{Observed System Performance}

Field performance data of the GEG Inventor 10-ton RTU and AAON 20-ton RTU were recorded continuously through July 2005. Figures 12 and 13 show application EER in terms of ambient temperature. Application EER is defined here as the energy efficiency ratio (ratio of Btu of cooling delivered divided by the electrical energy used to deliver this cooling) as measured in a given installation under prevailing field conditions. Application EER is distinguished from the manufacturer tested and reported ARI EER, which is measured in the laboratory, under controlled conditions, with an external static pressure of 0.3 inch water column, and (usually) with the smallest supply fan option installed ${ }^{10}$

As shown in the figure, the application EER for both RTUs varies with stage of cooling. Stage- 1 cooling (single compressor) has a lower EER because fixed accessory energy use (notably fan power) is a larger fraction of total energy use, and the EER is therefore lower. In the case of stage- 2 cooling (both compressors operating), the fixed energy use is now a smaller fraction of the total; the resulting EER is therefore higher.

Figures 14 and 15 present the application EER in terms of ambient dry-bulb minus entering wet-bulb temperature- - a measure of "lift." Presenting the data in this manner reduces scatter because both of the conditions that most strongly affect EER are accounted for ${ }^{11}$. Thus the scatter in Figures 14 and 15 is greatly reduced ( halved) compared to the previous two plots because most of the sensitivity to entering air conditions is now accounted for. Note that the scatter is still somewhat larger in Figure 15 (GEG) than in Figure $14(\mathrm{AAON})$. The reason may be that the subcooling and desuperheating sink temperature is not as well correlated with either $\mathrm{T}_{\mathrm{ODB}}$ or $\mathrm{T}_{\mathrm{EWB}}$ as we might wish. This is an issue for rating, as well as performance monitoring, of any kind of cooling technology that rejects heat to more than one sink (see, e.g. Hadley 2000). In this case, evaporatively-cooled return-air is used by the GEG for desuperheating and subcooling but return-air humidity could not be used in constructing an EER model because it was not measured.

One thing that is not comparable between the two monitored units is specific $\left(\mathrm{kW} /\right.$ ton) fan power ${ }^{12}$. The AAON fan draws $5.3 \mathrm{~kW}$ while GEG fan draws only $1.1 \mathrm{~kW}$. On a per-ton basis, the AAON fan is seeing twice as big an aerodynamic load, i.e., a higher specific air flow rate together with a higher external static pressure (ESP). ARI tests are all performed with 0.3 inches water column external static pressure so that this aspect of application-EER is eliminated in the ARI ratings. We therefore normalize the fan power of the unit that is farthest from the ARI test condition (in this case the unit with the higher specific fan power) so that both units are modeled as having the same specific fan power. See Appendix J for further discussion of specific fan power.

\footnotetext{
${ }^{10}$ It is in the manufacturer's interest to select and sheave the test unit's fan motor such that a good compromise between EER (best at low airflow) and capacity (best at high airflow) is achieved in the ARI test.

${ }^{11}$ This relationship is an aid to understanding the data; note that the EER models used in the spreadsheet calculations (Appendix $\mathrm{G}$ and $\mathrm{H}$ ) treat $T_{E W B}$ and $T_{O D B}$ as separate explanatory variables because the sensitivities of EER to $T_{E W B}$ and $T_{O D B}$ are actually somewhat different.

${ }^{12}$ Specific fan power is found to vary widely among applications for a number of reasons; in this case the baseline unit has a high cfm-per-square-foot airflow requirement because it serves a high-ceiling ballroom.
} 


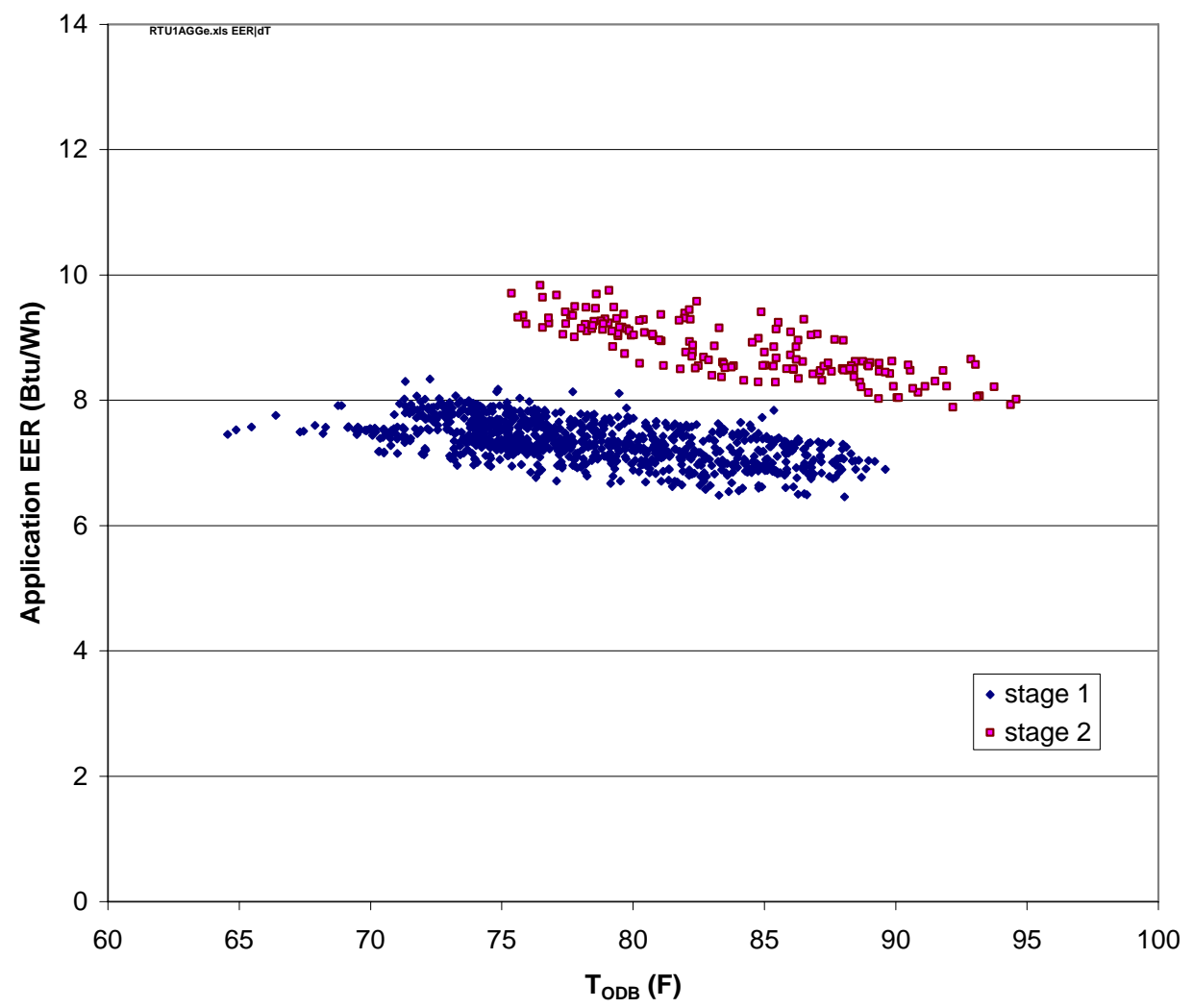

Figure 12. AAON RTU Performance as a Function of Outdoor Temperature

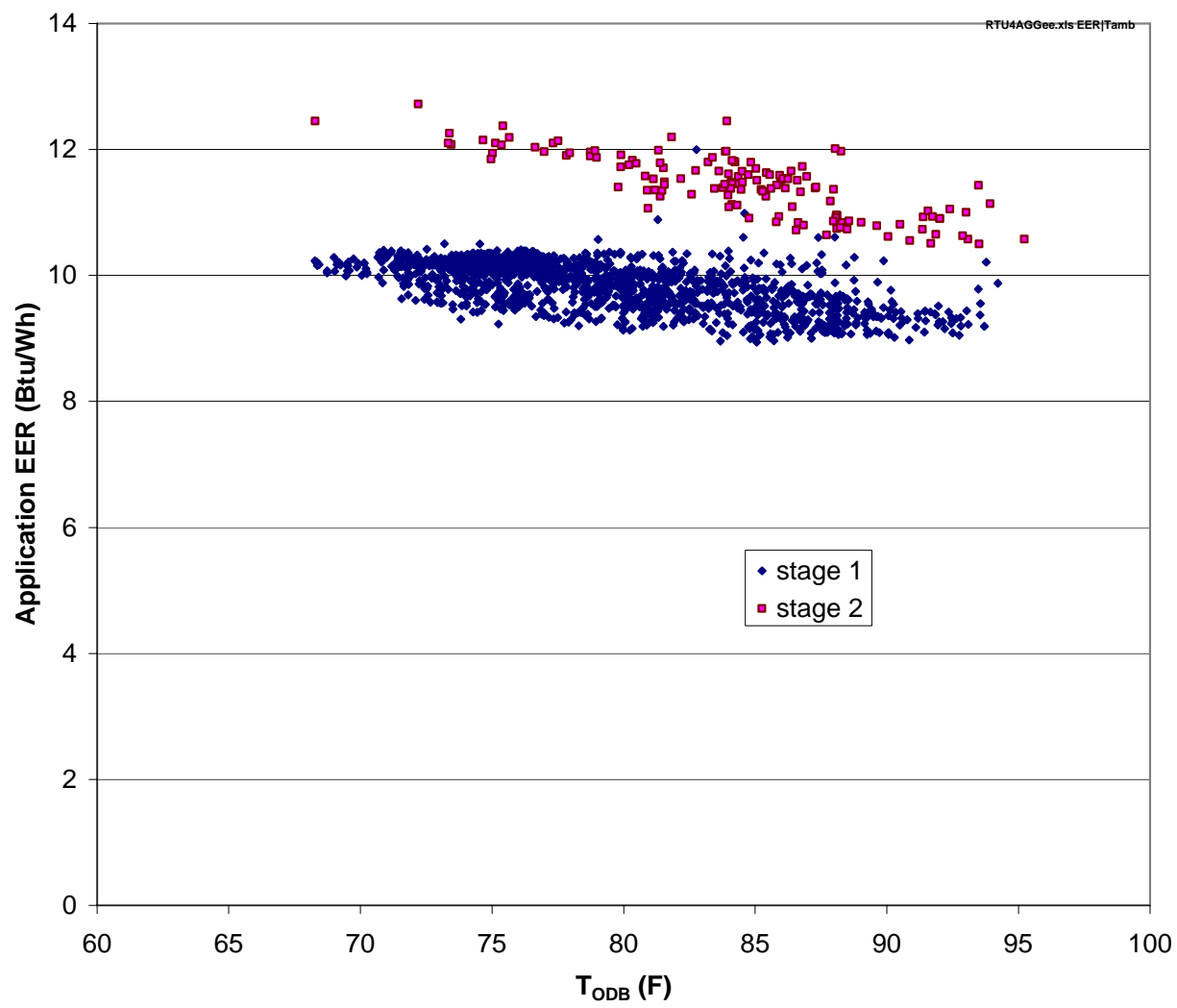

Figure 13. GEG RTU Performance as a Function of Outdoor Temperature 


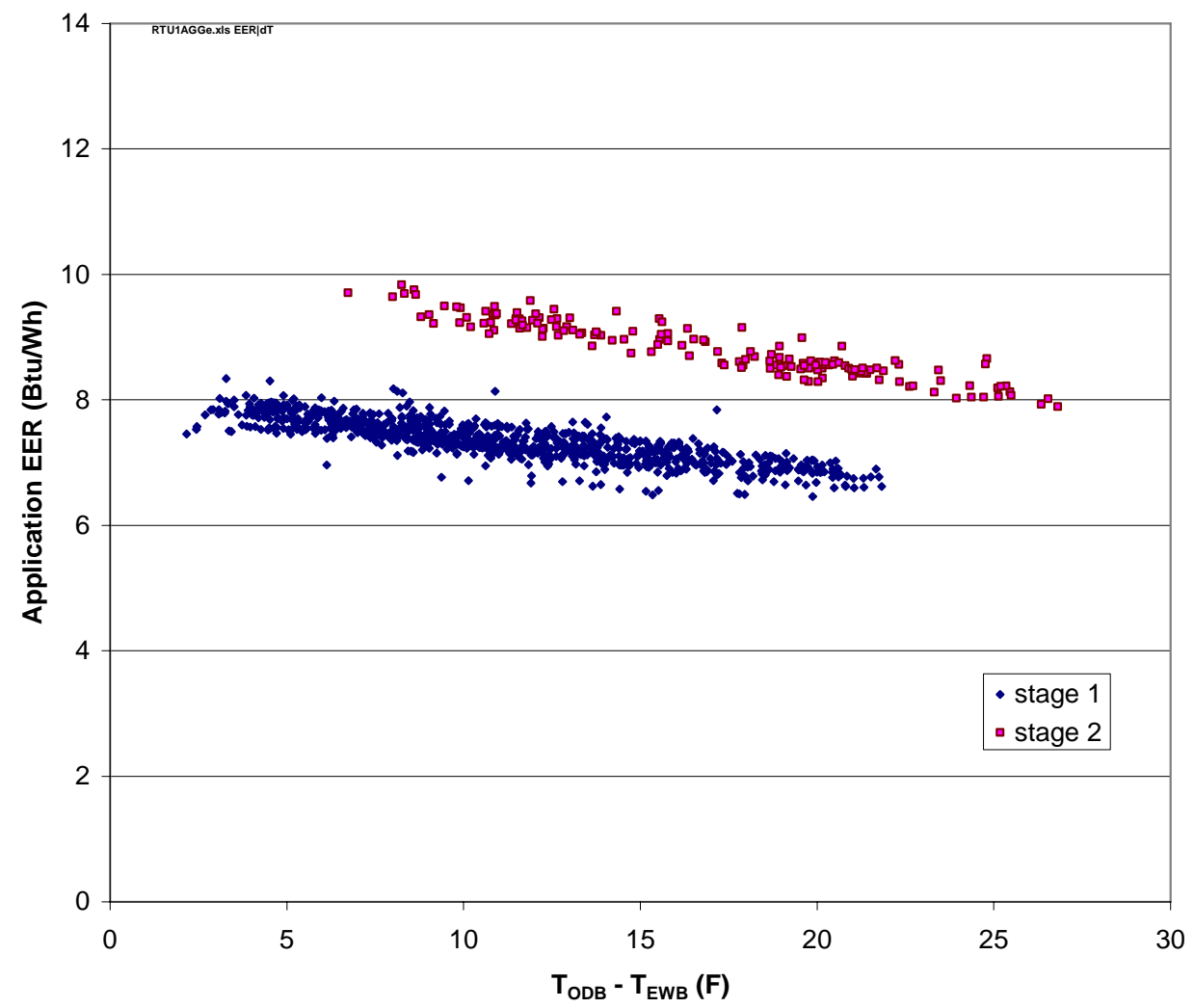

Figure 14. AAON Performance as a Function of Temperature Difference

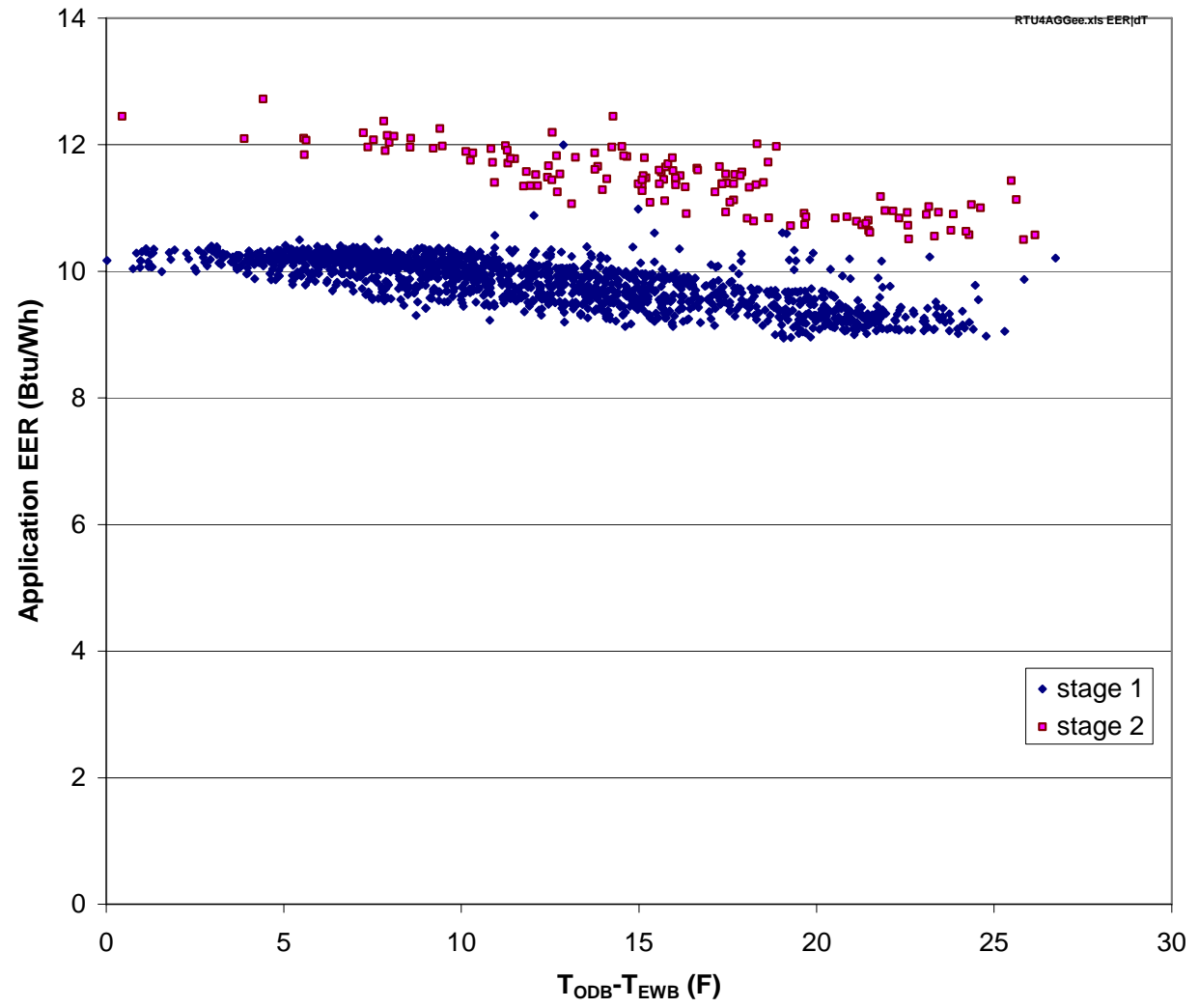

Figure 15. GEG Performance as a Function of Temperature Difference 


\section{Performance Model and Comparative Results}

With the large amount of data and range of conditions observed during the June-July 2005 monitoring period, we were able to characterize performance of both monitored units. Performance is represented as a function of conditions for each unit so that we can estimate annual energy use for a given building and climate. The performance of baseline and GEG equipment is reported in three ways: 1 ) in terms of application EER, 2) in terms of annual energy use for a hypothetical building in eight climates, and 3) in terms of life-cycle cost comparison of the two technologies in the same building and climates under various financial parameters.

\section{Performance at ARI Standard (Full-Load) and Part-Load Rating Conditions}

The results of linear regressions are presented in Appendix $\mathrm{G}$ for a simple model that treats EER as a linear function of $T_{E W B}$ and $T_{O D B}$. The ODB and EWB coefficients show that EER is more sensitive to ODB than to EWB and capacity is more sensitive to EWB. These trends are expected and reflected in typical unit performance tables provided by a manufacturer based on controlled laboratory tests.

To evaluate application EER at a given $T_{E W B}$ and $T_{O D B}$ one simply plugs the temperature values, e.g., $T_{E W B}=$ $67^{\circ} \mathrm{F}$ and $T_{O D B}=80^{\circ} \mathrm{F}$, into the model. To estimate annual energy use, one plugs in the temperatures for each bin (defined by a narrow range of $T_{O D B}$ and the corresponding mean coincident $T_{E W B}$ reported in the climate data for a specified location), corrects for cycling losses, multiplies by the number of hours of load at the given bin condition and sums across temperature bins.

Comparing the two RTUs, as instrumented and analyzed at Fort Gordon, results in a well-defined performance difference. Two useful points on the performance curve are given by the table, reproduced in Appendix H, from ARI standard 340/360. These two points are the stage-1 performance at ARI part-load conditions, $T_{E W B}=67^{\circ} \mathrm{F}$ and $T_{O D B}=80^{\circ} \mathrm{F}$, and the stage- 2 performance at ARI full-load conditions, $T_{E W B}=67^{\circ} \mathrm{F}$ and $T_{O D B}=95^{\circ} \mathrm{F}$.

After normalizing for specific fan power (Appendix G), the high-efficiency GEG RTU stage-2 application EER at ARI-defined full-load conditions is about $16 \%$ better than that of the baseline machine's application EER. Under the ARI-defined part-load conditions, the GEG unit's stage-1 application EER is about $8 \%$ better $^{13}$. These results are summarized in Table 3 .

Table 3 Field Performance Results (Application EER normalized for specific fan power) for the AAON and GEG RTUs.

\begin{tabular}{|l|c|c|c|}
\hline & AAON RTU & GEG RTU & \% Difference \\
\hline $\begin{array}{l}\text { Application EER at ARI full-load } \\
\text { conditions - stage-1 cooling }\end{array}$ & 7.84 & 8.94 & $14.0 \%$ \\
\hline $\begin{array}{l}\text { Application EER at ARI full-load } \\
\text { conditions - stage-2 cooling }\end{array}$ & 9.00 & 10.48 & $16.4 \%$ \\
\hline $\begin{array}{l}\text { Application EER at ARI part-load } \\
\text { conditions - stage-1 cooling }\end{array}$ & 9.00 & 9.73 & $8.1 \%$ \\
\hline $\begin{array}{l}\text { Application EER at ARI part-load } \\
\text { conditions - stage-2 cooling }\end{array}$ & 10.48 & 11.61 & $10.8 \%$ \\
\hline $\left.\begin{array}{l}\left.\text { ARI full-load conditions are } \mathrm{TODB}_{\mathrm{ODB}}=95^{\circ} \mathrm{F}, \mathrm{T}_{\mathrm{EWB}}=67^{\circ} \mathrm{F}\right) \\
\text { ARI part-load conditions are (T⿰D口⿻ }\end{array} 8^{\circ} \mathrm{F}, \mathrm{T}_{\mathrm{EWB}}=67^{\circ} \mathrm{F}\right)$ & \\
\hline
\end{tabular}

It is important to remember that these field measurements are not comparable to the laboratory-generated ARI EER test values. The laboratory EER values are the result of a very prescribed and controlled test

${ }^{13}$ Before adjusting for the supply fan conditions (Figures 12-15), the GEG machine's stage-2 application EER at ARI Standard (full-load) Rating conditions is about 32\% better than that of the baseline machine and the stage-1 EER is about $34 \%$ better. However, the supply fan aerodynamic load (static pressure and $\mathrm{cfm} / \mathrm{ton}$ ), which determine specific fan power of each unit differ in a way that gives the baseline unit a substantially lower application EER than would have been achieved with a more comparable $\mathrm{cfm} / \mathrm{ton}$ and ESP. 
procedure while the application EER values are from field-generated data obtained under a variety of realworld conditions of weather, operational practice, and system loading. The configurations of compared systems are not always identical and may require simple adjustments, such as the specific fan power normalization, to make performance comparisons useful.

\section{Seasonal Performance}

To estimate seasonal performance we must specify a climate and a load characteristic in addition to the performance map described in the previous section. To compare the life-cycle costs of two RTUs, we must also specify energy prices, the cost of money, an analysis period, and the initial and annual maintenance costs for the units to be compared.

The load model developed for the UAC cost estimator (www.pnl.goc/uac ${ }^{14}$ ) and a bin analysis method that uses typical meteorological year (Hall et al. 1978; Marion and Urban 1995) weather data are used to estimate annual energy consumption for a given load and climate.

The load model assumes a sensible cooling load directly proportional to outdoor temperature and a latent load directly proportional to the product of outdoor humidity (mass ratio of water vapor to dry air) and outside air flow rate. An ideal enthalpy control is assumed and a fixed minimum outside air flow rate ( $10 \%$ in this analysis) is specified by the user. The peak load (for sizing purposes) is assumed to occur at the ASHRAE $0.4 \%$ dry- and wet-bulb temperatures with the minimum $(40 \mathrm{scfm} / \mathrm{ton})^{15}$ outside air-flow setting. The cooling balance point is assumed to be $50^{\circ} \mathrm{F}$.

The foregoing assumptions determine the full-load-equivalent operating hours (FLEO hours or FLEOH) of the hypothetical building used to perform the LCC analysis across climates (Somasundaram et al. 2002; Nemeth et al. 1995). Thus the FLEOH parameter is a way of approximately describing a building's annual air conditioning $(\mathrm{A} / \mathrm{C})$ load shape in a single number using the following definition:

$$
\text { FLEOH }=\frac{\sum_{t=1}^{8760} Q(t)}{Q_{\text {design }}}
$$

where $Q(t)$ is the time series of hourly coil loads and $Q_{\text {design }}$ is the ASHRAE design load and 8760 is the number of hours in a year (Somasundaram et al. 2002).

After the hourly coil load is evaluated by the load model for a given bin temperature, the $1^{\text {st }}$ - and $2^{\text {nd }}$-stage duty fractions are calculated. The duty fractions are adjusted to account for cycling loss. The $1^{\text {st }}$ - and $2^{\text {nd }}$ stage EER models are then applied to determine average $\mathrm{kW}$ for a bin, and this is multiplied by the number of annual bin hours to get bin $\mathrm{kWh}$. The resulting $\mathrm{kWh}$ numbers for each bin are then summed over all bins to get the annual operating energy.

\footnotetext{
${ }^{14}$ The UAC cost-estimator was developed for the original procurement effort that motivated this demo.

${ }^{15} 40 \mathrm{scfm}$ per ton of cooling capacity corresponds to about $10 \%$ outside air, a typical minimum outside air fraction.
} 


\section{Life-Cycle Cost Results}

Having computed annual operating energy, the present value of energy cost is plugged into the standard LCC analysis framework to arrive at the comparative net present value (NPV) term. The unit to be replaced is assumed to be at the end of its useful life ${ }^{16}$. Energy prices, cost of money as annual percentage rate, an analysis period, and the initial and annual maintenance costs for the units to be compared in this analysis are presented in Table 4.

Table 4. Economic Parameters for Life-Cycle Cost Calculation

\begin{tabular}{|l|c|c|}
\hline Category & Baseline & Alternative \\
\hline Equipment Cost $(\$)$ & 3,824 & 5,525 \\
\hline Maintenance $(\$ / \mathrm{yr})$ & 100 & 125 \\
\hline Maintenance Present Value (\$) & $1,189.57$ & $1,486.97$ \\
\hline Discount Rate (\%/year) & 4.9 & 4.9 \\
\hline Fuel Escalation Rate (\%/year) & 1.8 & 1.8 \\
\hline Analysis Period (yrs) & 15 & 15 \\
\hline Electricity Rate $(\$ / \mathrm{kWh})$ & 0.08 & 0.08 \\
\hline
\end{tabular}

The seasonal energy bin calculations and LCC analysis are readily performed in a spreadsheet format, as illustrated in Appendix I. The results of these analyses are summarized for eight locations in Table 5.

Referring to Table 5, the GEG RTU, in comparison to the baseline AAON RTU, is seen to be costeffective in applications where the annual full-load equivalent operating hours (FLEOH) are greater than about 1800. This is not an exact number because the seasonal performance also depends not just on the total FLEOHs but also on the distribution of FLEOHs between stage- 1 and stage-2 operation, which is accounted for in the analysis.

Note that the FLEOH parameter describes both climate and building characteristic aspects of a cooling load. In the UAC analysis a single number, the balance point, is used to explain the interaction of building load coefficient, average solar and internal gains, and cooling setpoint. For many buildings, the balance point and design load are sufficient to explain most of the variation among building cooling load characteristics. Treating FLEOH as a function of climate only (Nemeth et al. 1995) is not generally recommended for making final life-cycle cost estimates.

\footnotetext{
${ }^{16}$ The NPV comparisons are also valid for selection of equipment in new construction and replace-onfailure scenarios; replacement of standard-efficiency equipment before the end of its useful life will result in a less attractive NPV.
} 
Table 5. Summary of Life-Cycle Cost Analyses for Selected Locations

\begin{tabular}{|l|cc|cc|cc|c|}
\hline & \multicolumn{2}{|c|}{ Annual Load } & \multicolumn{2}{c|}{ Baseline } & \multicolumn{2}{c|}{ New Technology } & NPV \\
City & FLEOH & kBtu & kWh & PV\$ & kWh & PV\$ & \$ \\
\hline Atlanta, GA & 1680 & 193168 & 19011 & 18092 & 17439 & 16596 & -503 \\
Augusta, GA & 2864 & 329389 & 31412 & 29894 & 29001 & 27599 & 296 \\
Chicago, IL & 1159 & 133243 & 13389 & 12742 & 12269 & 11676 & -933 \\
Denver, CO & 998 & 114730 & 11773 & 11204 & 10779 & 10258 & -1053 \\
Phoenix, AZ & 1969 & 226378 & 26254 & 24985 & 22961 & 21851 & 1136 \\
San Francisco, CA & 1181 & 135851 & 8916 & 8485 & 8428 & 8020 & -1534 \\
Seattle, WA & 815 & 93685 & 6956 & 6620 & 6523 & 6208 & -1586 \\
Baltimore, MD & 1378 & 158491 & 15718 & 14958 & 14408 & 13712 & -752 \\
\hline
\end{tabular}

Manufacture of this equipment on a larger scale can be expected to reduce costs to the point where it is more broadly cost-effective. The baseline and GEG 10-ton unit costs used in the Table 5 analyses are $\$ 3824.00$ and $\$ 5525.00$ respectively. If the new technology cost is assumed to drop as sales increase to $\$ 4674.50$ (i.e., the original cost difference is halved) for a 10 -ton unit, the life-cycle cost situation improves, as shown in Table 6.

\section{Table 6. Life-Cycle Cost Comparison with Lower GEG Cost Assumed}

\begin{tabular}{|l|cc|cc|cc|c|}
\hline & \multicolumn{2}{|c|}{ Annual Load } & \multicolumn{2}{c|}{ Baseline } & \multicolumn{2}{c|}{ New Technology } & NPV \\
City & FLEOH & kBtu & kWh & PV\$ & kWh & PV\$ & \$ \\
\hline Atlanta, GA & 1680 & 193168 & 19011 & 18092 & 17439 & 16596 & 348 \\
Augusta, GA & 2864 & 329389 & 31412 & 29894 & 29001 & 27599 & 1147 \\
Chicago, IL & 1159 & 133243 & 13389 & 12742 & 12269 & 11676 & -82 \\
Denver, CO & 998 & 114730 & 11773 & 11204 & 10779 & 10258 & -202 \\
Phoenix, AZ & 1969 & 226378 & 26254 & 24985 & 22961 & 21851 & 1986 \\
San Francisco, CA & 1181 & 135851 & 8916 & 8485 & 8428 & 8020 & -683 \\
Seattle, WA & 815 & 93685 & 6956 & 6620 & 6523 & 6208 & -736 \\
Baltimore, MD & 1378 & 158491 & 15718 & 14958 & 14408 & 13712 & 98 \\
\hline
\end{tabular}

The sensitivity of NPV to purchase price, electricity and maintenance costs is shown in Appendix I. The assumed initial and annual maintenance costs for the baseline unit are $\$ 3824.00$ and $100.00 / \mathrm{yr}$ for all sensitivity NPV calculations. The sensitivity of NPV to purchase price, electricity and maintenance costs is shown in Table I-2. The table looks at two values of initial cost (\$4674.50 and \$5525.00), three values of annual maintenance cost $(112.50,125$, and $150 \$ / \mathrm{yr})$ and three values of effective cost per $\mathrm{kWh}(0.08$, 0.10 , and $0.12 \$ / \mathrm{kWh}$ ) and reports the net present value for all combinations of these life-cycle cost parameters.

There is a retrofit version of the technology that may be LCC-effective in many applications. The retrofit package adds desuperheating and subcooling in a small package whose footprint is about $20 \%$ that of the typical existing package DX air-conditioning unit to which it is attached. Regardless of the details of implementation, however, the user must make a commitment to periodically check the evaporative cooling subsystem, which is mechanically similar to a swamp cooler. 


\section{Conclusions}

Based on the data collected, analyzed and presented here, the GEG Inventor 1400 Series RTU showed a significant energy efficiency increase over the typical-efficiency AAON RTU. This increase, as reported by "application EER" and over the range of conditions measured in June-July 2005, showed an increase of $8 \%$ for stage- 1 cooling and $16 \%$ for stage- 2 cooling. Translating these savings into annual performance (an application seasonal energy efficiency ratio), and applying appropriate life-cycle cost economics, results in a NPV of approximately $\$ 295$ (about $10 \%$ of the purchase price difference) for the GEG RTU over the baseline AAON RTU installed at Fort Gordon in Augusta, Georgia.

Using a modeled extrapolation of the data to other climate zones, assuming similar baseline equipment and loading, results in an estimated annual full-load equivalent operating hour (FLEOH) cut-off for cost

effectiveness of about 1,800 hours. In other words, with the assumptions presented here, installation of the GEG Inventor 1400 Series would be life-cycle cost-effective in a building (occupancy schedule, internal gains, envelope characteristics, climate) having a FLEOH value of greater than 1,800 hours.

In general, however, the performance differential of the GEG RTU over the typical-efficiency RTU is not enough to overcome its first-cost premium of over $40 \%$.

Lessons learned about conducting field performance assessments of this type equipment are summarized in Appendix J. 


\section{Appendices}

Appendix A: Refrigerant-Side Capacity Measurement .............................................................................29

Appendix B: Compressor Mass Flow Performance Map ............................................................................

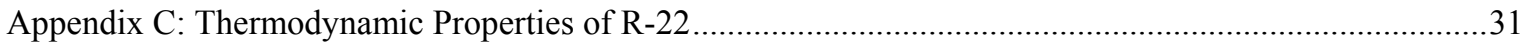

Appendix D: Wet-bulb and Dew-Point Temperatures ...............................................................................3

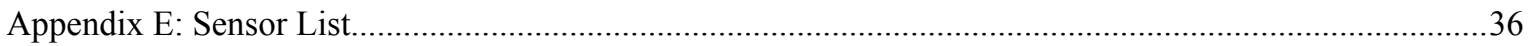

Appendix F: Photo Documentation of RTU and Monitoring Equipment ………........................................37

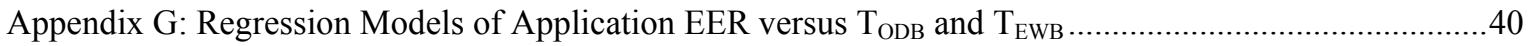

Appendix H: ARI Standard 340/360 Rating Conditions ..........................................................................

Appendix I: Energy and Life-Cycle Cost by the UAC Cost Estimator ........................................................44

Appendix J: Issues in Measurement of Package A/C Field Performance …………......................................47 


\section{Appendix A. Refrigerant-Side Capacity Measurement.}

Heat absorbed by the refrigerant as it passes through the evaporator is expressed as a change in enthalpy, i.e., the difference between the enthalpy of the vapor leaving the evaporator and the liquid entering the $\mathrm{TXV}^{17}$. The TXV and distribution lines are treated as part of the evaporator because they have a relatively small surface area and are in the air stream. The evaporator refrigerant-side heat rate in Btu/hour $(\mathrm{Btu} / \mathrm{h})$ is thus given by:

where

$$
Q_{r e}=m\left(h_{s}-h_{l}\right)
$$

$m$ is the refrigerant mass flow rate in $1 \mathrm{bm} /$ hour,

$h_{s}=h_{\text {vap }}\left(T_{s}, P_{s}\right)$ vapor enthalpy at compressor suction port conditions, and

$h_{l}=h_{\text {liq }}\left(T_{l}, P_{\nu}\right)$ liquid enthalpy at liquid line temperature ahead of the TXV.

The mass flow rate is estimated using a compressor performance map, as described in Appendix B. The enthalpies of a pure vapor and pure liquid are functions of temperature and pressure only, as indicated in Appendix C.

The suction line temperature is measured where the suction line passes from the supply fan inlet plenum into the compressor compartment, and the liquid line temperature is measured where the liquid line passes from the compressor compartment into the supply fan inlet plenum. Temperatures are measured by type $\mathrm{T}$ thermocouples using 24 AWG, Teflon-insulated, special-limits wire. Each bare junction is insulated electrically from the copper refrigerant line by 3-mil polyimide tape.

The thermocouple wire makes four helical turns about the line on its approach to the sensing junction; the lead wire and junction are held under tension and bonded to the pipe with a bead of RTV silicone overwrapped with silicone tape under tension. Lead wire, junction and pipe are well-insulated 5 inches upstream and downstream of the sensing junction. These measures minimize conduction loss error, i.e., the difference between junction temperature and average temperature of the refrigerant in the line at the measuring location.

The liquid line pressure is assumed equal to the discharge pressure because the pressure drops through the desuperheater, condenser and subcooler are relatively small and the liquid enthalpy is very insensitive to pressure. Discharge pressure is measured at the high side service port (Schrader valve). Suction pressure is measured at the low-side service port (Schrader valve),which is just downstream of where the suction line passes from the supply air fan inlet plenum to the compressor compartment.

With accurate measurements of compressor power, $P_{c m p r}$, energy balance can be checked:

or by

$$
Q_{r e}+P_{c m p r}+m\left(h_{l}-h_{d}\right)=0
$$

$$
P_{c m p r}+m\left(h_{s}-h_{d}\right)=0
$$

where

$$
h_{d}=h_{\text {vap }}\left(T_{d}, P_{d}\right) \text { vapor enthalpy at compressor discharge port conditions. }
$$

\footnotetext{
${ }^{17}$ The thermostatic expansion valve (TXV) maintains a nearly constant superheat of 10 to $20^{\circ} \mathrm{F}$ by regulating the flow of liquid refrigerant into the evaporator. The refrigerant begins to vaporize at the TXV outlet.
} 


\section{Appendix B. Compressor Mass Flow Performance Map}

A positive-displacement compressor in good operating condition is essentially a constant volumetric flow rate device. Deviations from this behavior result from clearance volume effects, bypass leakage, flow losses (mainly at the inlet port), and thermal dissipation - collectively modeled as volumetric efficiency. Volumetric efficiency is mainly a function of pressure ratio and always less than $100 \%$ (Threlkeld 1970, 1998).

One does not usually have access to a given manufacturer's primary test data. Curves, of the form specified in ARI standard 340/360 (ARI 2000), that have been fit to the test data may sometimes be provided by a manufacturer. The fit coefficients, if provided at all, are given without any information about goodness of fit or about the statistical significance of each coefficient. Moreover, the ARI curves used by compressor manufacturers are for an assumed, fixed amount of suction superheat, $20^{\circ} \mathrm{F}$ above the boiling point at any given suction pressure. The mass flow rate may or may not be reported. If not, it can be estimated from the capacity relation via (A-1) and the $15^{\circ} \mathrm{F}$ liquid subcooling condition specified in ARI $340 / 360$.

The best theoretical performance of a vapor-compression machine is obtained with zero superheat but in practice a finite superheat is needed to protect the compressor from liquid ingestion. The tradeoff between average system performance and risk of compressor damage is largely determined by the ability of the thermal expansion valve - which controls refrigerant flow into the evaporator based on superheat - to maintain a small superheat safety margin.

We observed in RTU 4 that superheat ranges between 10 and $15^{\circ} \mathrm{F}$. This range corresponds to a significant variation in suction density and a significantly higher mass flow rate than would have been inferred assuming the specified ARI suction vapor condition. We therefore fit a semi-empirical model that has actual suction density (based on measured temperature, $T$, and pressure, $P$ ) as one of its independent variables ${ }^{18}$ to the compressor mass flow data provided by Carlyle and Copeland ${ }^{19}$.

The semi-empirical model used here to evaluate refrigerant-side capacity is

$$
\dot{m}=\rho \dot{V}\left(\rho, P_{s}, P_{d}\right)=\rho \dot{Q}(\rho, r)
$$

where

$r=P_{d} / P_{s}=$ ratio of absolute pressures,

$\rho=$ suction vapor density as evaluated in Appendix $\mathrm{C}$, and

$\dot{V}(\rho, r)=c_{1}+c_{2} r+c_{3} r^{2}+c_{4} \rho r^{2}+c_{5} \rho r^{3} c_{6} \rho^{3} r$ is the volumetric flow rate.

The coefficients obtained by fitting the model to the points on the ARI compressor performance map provided by Carlyle for the model SRY452 $\mathrm{HC}^{20}$ are $c_{1}=484.9$,

$c_{2}=-33.676, c_{3}=4.1528, c_{4}=3.2618, c_{5}=-0.7865$, and $c_{6}=1.0669$ with $V$ in $\mathrm{ft}^{3} / \mathrm{h}$ and $\rho$ in $\mathrm{lbm} / \mathrm{ft}^{3}$. In the limit of $r=1$ and $\rho=0$, the volumetric flow rate is $V(\rho, r)=455.4 \mathrm{ft}^{3} / \mathrm{h}$.

\footnotetext{
${ }^{18}$ Jahnig, D.I., D.T. Reindl, S.A. Klein. 2000. A semi-empirical method for representing domestic refrigerator/freezer compressor calorimeter test data, ASHRAE Transactions, 101(2)

${ }^{19}$ Courtesy of Michael Collins, Carlyle application engineer and Hung Pham, Copeland director of research.

${ }^{20}$ RTU4 uses two Carlyle SRY425HC compressors; RTU1 uses two Copeland ZR108KCTF5 compressors.
} 


\section{Appendix C. Thermodynamic Properties of R-22}

For capacity calculations and evaluation of the compressor flow rate model, we need to estimate the density of superheated refrigerant vapor and the enthalpies of superheated vapor and the subcooled liquid over a range of pressure and temperature. We also need the pressure-temperature curve for liquid and vapor in equilibrium to compute the degree of superheat, given T,P of a vapor, or subcooling, given T,P of a liquid. These routines are based on the work of Srinivas Katipamula, PNNL, and Kevin Clavin, AGA Laboratories, whose assistance the authors are pleased to gratefully acknowledge.

\section{Table C-1: Saturation Temperature}

FUNCTION PsiaR22Tsat (psat) STATIC

'AGA Lab 1992 returns Tsat(F) +/- 0.15 over 0:130degF given psat (psia)

DIM $\mathrm{px}, \mathrm{xx}$

$\mathrm{px}=\mathrm{psat} * .01$

$\mathrm{xx}=\mathrm{px} *(-13.543+\mathrm{px} * 1.2867)$

PsiaR22Tsat $=-57.727+\mathrm{px} *(191.35+\mathrm{px} *(-127.64+\mathrm{px} *(57.171+\mathrm{xx})))$

'PsiaR22Tsat $=-57.727+\mathrm{px} *(191.35+\mathrm{px} *(-127.64+\mathrm{px} *(57.171+\mathrm{px}(-13.543+$

$\mathrm{px} * 1.2867)$ )) )

END FUNCTION

\section{Table C-2: Vapor Enthalpy}

FUNCTION hgR22 (psat, TVap) STATIC

'AGA Lab 1992 enthalpy (Btu/lbm) given psat (psia) and Tvap>Tsat (F)

DIM $\operatorname{shT}, \mathrm{xx}, \mathrm{x} 2, \mathrm{x} 3, \mathrm{hg}$

shT $=$ Tvap - Psiar22Tsat (psat)

hgsat $=102.62+$ psat $*(.07299-$ psat $* .00014)$

$\mathrm{xx}=.01 * \mathrm{shT}$

$\mathrm{x} 2=.1974+\mathrm{xx} *(-.0401+\mathrm{xx} * .0202)$

$\mathrm{x} 3=$ hgsat $/ 107.56$

$\mathrm{x} 3=-3.2444+\mathrm{x} 3 * 4.2444$

hgR22 $=\mathrm{x} 2 * \mathrm{x} 3 * \mathrm{shT}+$ hgsat

END FUNCTION' hgR2 2 -

\section{Table C-3: Liquid Enthalpy}

\section{FUNCTION hfR22 (psat, Tliquid) STATIC}

'AGA Lab 1992 enthalpy (Btu/lbm) given psat (psia) and Tliquid<Tsat (F)

DIM SCT, $\mathrm{xx}, \mathrm{x} 2, \mathrm{x} 3, \mathrm{hg}$

SCT = PsiaR22Tsat (psat) - Tliquid

$\mathrm{xx}=.01 *$ psat

hfsat $=-.1501+\mathrm{xx} *(32.32+\mathrm{xx} *(-8.9+\mathrm{xx} * 1.16))$

$\mathrm{xx}=.01 *$ hfsat

$\mathrm{x} 2=.2635+\mathrm{xx} *(.0177+\mathrm{xx} *(.02758+\mathrm{xx} * .0181))$

$\mathrm{x} 3=\mathrm{SCT} * \mathrm{x} 2$

hfR22 = hfsat $-\mathrm{x}^{3}$

END FUNCTION'hfR22

\section{Table C-4: Vapor Density}

\section{FUNCTION vpsv ( $\mathrm{p}, \mathrm{tg})$ STATIC}

'Static Function vpsv(p As Double, tg As Double, nr As Integer) As Double

'specific volume (ft3/lbm) of refrigerant vapor given pressure (psia) and temperature (F)

' from NBS model TRPUMP, Revised by Srinivas Katipamula, Texas A\&M

CONST $\mathrm{al}=0 \#, \mathrm{~b} 1=.002, \mathrm{Cl}=0 \#$

CONST a2 $=-4.353547, \mathrm{~b} 2=.002407252 \#, \mathrm{c} 2=-44.066868 \#$

CONST $\mathrm{a} 3=-.017464, \mathrm{~b} 3=.0000762789, \mathrm{c} 3=1.483763, \mathrm{a} 4=.002310142, \mathrm{~b} 4=-.000003605723, \mathrm{c} 4=0$

CONST $\mathrm{a} 5=-.00003724044, \mathrm{~b} 5=.5355465 \mathrm{e}-7, \mathrm{c} 5=-.0001845051, \mathrm{a} 6=136338700, \mathrm{~b} 6=-167261.2, \mathrm{c} 6=0$

CONST $\mathrm{k}=4.2$, alpha $=548.2, \mathrm{cpr}=0 \#$

CONST tc $=664.5, \mathrm{pc}=721.906, \mathrm{VC}=.030525, \mathrm{R}=.124098$

DIM msg AS STRING, $t$

$t=t g+t f r$ 'convert $F$ to $R$

IF $(t<=0 \#)$ THEN

msg = "Error in calling --vpsv-- Temperature less than zero (R) -->"

$\mathrm{msg}=\mathrm{msg}+\operatorname{STR} \$(t)$

PRINT msg: ERROR (199)

END IF

IF $(\mathrm{p}<=0 \#)$ THEN

msg = "Error in calling --vpsv--"

$\mathrm{msg}=\mathrm{msg}+$ "Pressure less than zero (psia) -->>" + STR\$ (p)

END IF

PRINT msg: ERROR (199)

' compare tsat with $t$ :

IF $\mathrm{tg}<\mathrm{t}$ THEN

msg = "Error in calling --vpsv--"

$\mathrm{msg}=\mathrm{msg}+$ "Saturation temperature greater than input "

$\mathrm{msg}=\mathrm{msg}+$ "temperature" + STR\$ $(t-t f r)+\operatorname{STR} \$(t)$

END IF

RRINT msg: ERROR (199) 


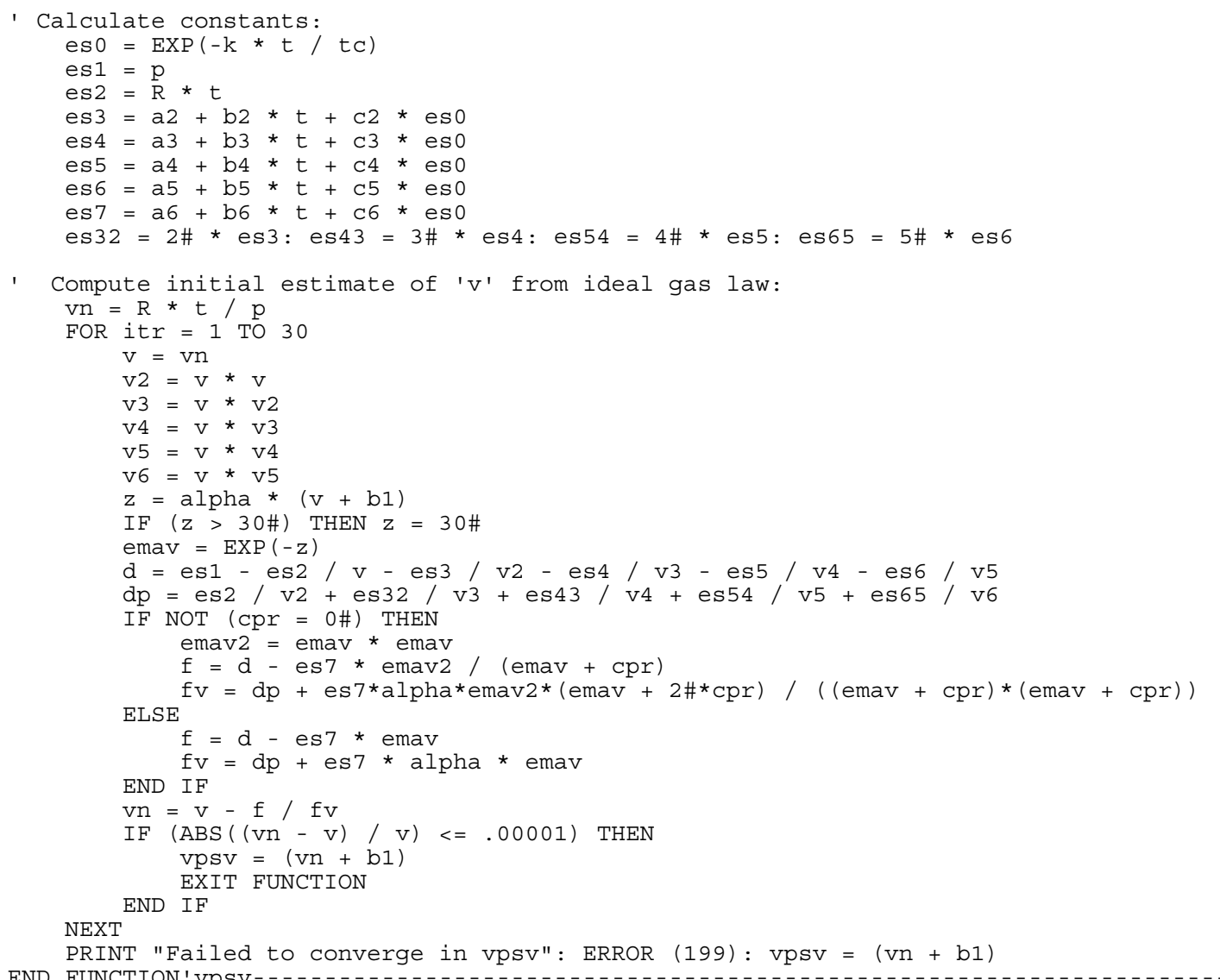




\section{Appendix D. Wet-bulb and Dew-Point Temperature Calculations.}

The relations presented in Appendices A and B show that capacity and EER of a given positive displacement refrigeration machine are functions mainly of suction density and suction and discharge pressures. However, the conditions of interest for design and life-cycle cost analysis of package A/C applications are outdoor dry-bulb temperature (straightforward) and entering air wet- and dry-bulb temperatures. Package equipment performance (capacity and EER) is specified in terms of these conditions. For this project it was therefore necessary to measure or derive the conditions and express them in a standard way.

Moist air conditions at a given barometric pressure may be represented by two variables, e.g., $(T, \varphi),(T, W)$, $\left(T, T_{w b}\right)$, or $\left(T, T_{d p}\right)$. Of these, $\mathrm{T}$ and $\varphi$, are currently the easiest to measure but, for historical reasons ${ }^{21}$, performance of DX systems is presented in terms of one of the other representations of the moist air state. For example ARI ratings, for both full- and part-load rating points, are made at $\left(T, T_{w b}\right)=\left(80^{\circ} \mathrm{F}, 67^{\circ} \mathrm{F}\right)$ mixed air conditions.

The equations for evaluating $W, T_{w b}$, or $T_{d p}$, given $(\mathrm{T}, \varphi)$ involve the ratio of molecular weights $(18.016$ $\mathrm{kg} / \mathrm{mole}$ for water, $28.016 \mathrm{~kg} / \mathrm{mole}$ for air), which is rounded to $18.016 / 28.966 \cong 0.622$ or $28.966 / 18.016 \cong$ 1.608 in this appendix but the ratios are evaluated with no loss of precision in the analysis program. The mole-fraction of water vapor, $x_{w}$, may be estimated from the measured relative humidity, $\varphi$, temperature, $T$, at the humidity sensor, and barometric pressure, $P$ :

$$
x_{w}=\varphi x_{w, s}=\varphi \frac{f_{s}(T, P) P_{w, s}(T)}{P}
$$

where $P_{w, s}(T)$ is the saturation pressure (pressure at which water, at temperature $T$, boils) and $x_{w, s}$ is the mole-fraction of saturated air at a given temperature and pressure $(T, P)$.

The empirical function, $f_{s}$, ranges between 1.0044 at $40^{\circ} \mathrm{F}$ and 1.0057 at $125^{\circ} \mathrm{F}$. The sea-level data [HVAC Guide, 1940, reproduced in Threlkeld (1970)], is well represented by a quadratic:

$$
f_{s}=0.0000002 T^{2}-0.000018 T+1.004811 \quad 0^{\circ} \mathrm{F} \geq T \geq 125^{\circ} \mathrm{F}
$$

An alternate form (Wobus, USNWRF Norfolk) that includes effect of pressure $(\mathrm{Pa})$, is:

$$
\left.f_{s}=1+4.5 \mathrm{e}-8 P+7.84 \mathrm{e}-10(T-12.5+7.5 \mathrm{e} 5 / P)\right)^{2} \quad-20^{\circ} \mathrm{C} \geq T \geq 50^{\circ} \mathrm{C}
$$

The humidity ratio (water vapor mass per unit dry air mass) is given by:

$$
W=0.622 \frac{x_{w}}{1-x_{w}} ; \quad W_{S}=0.622 \frac{x_{w, s}}{1-x_{w, s}}
$$

The dew point is the temperature, $T_{d p}$, at which saturation pressure equals the partial pressure of water vapor in the moist air sample, that is, the solution to:

$$
P_{w, s}\left(T_{d p}\right)=\varphi P_{w, s}(T)_{s}
$$

Wet-bulb temperature, $T_{w b}$, is evaluated by solving for the discharge temperature in an adiabatic saturation process - that is, by solving

$$
h\left(T_{w b}, W_{\text {sat }}\left(T_{w b}\right)\right)=h(T, W) .
$$

The enthalpy of moist air is given (Threlkeld 1970) by:

where

$$
h=h_{a}+\mu h_{a s}+h^{\prime}
$$

$$
\begin{aligned}
& \mu=W / W_{S} \\
& h_{a s}=1061.23+0.43917 W_{s}(\mathrm{Btu} / \mathrm{lbm})
\end{aligned}
$$

\footnotetext{
${ }^{21}$ Although expensive and tricky, wet-bulb or dew-point temperature is still the standard for laboratory humidity measurement; however, reliable low-cost RH sensors are now used routinely for field measurements of moist air humidity. Wet-bulb temperature is the single most important indoor air condition with respect to package $\mathrm{A} / \mathrm{C}$ performance rating.
} 


$$
\begin{aligned}
& h^{\prime}=\frac{\mu(1-\mu) B(T)}{1+1.608 \mu W_{S}} \text { and } \\
& B(T) \sim \exp (0.052 T-8.66)(\mathrm{Btu} / \mathrm{lbm}) \text { may be taken to be zero below } 96^{\circ} \mathrm{F} .
\end{aligned}
$$

The subroutines to evaluate moist air properties by the foregoing expressions are listed in Table D-1. Note that the iterative solution of wet-bulb temperature is evaluated by a finite number (13) of interval bisections so that there is no need for a stopping test and no risk of non-convergence.

\section{Bibliography and References for Appendix D}

Goff, J.A. and S. Gratch, 1940. HVAC Guide, Amer. Soc. Heating and Ventilating Engineers, 37, p.14

Goff, J.A., 1949. "Standardization of the thermodynamic properties of moist air," Trans. ASHVE, 55, pp.459-484)

Goff, J.A. and S. Gratch, 1945. "Thermodynamic properties of moist air," Trans. ASHVE, 51, pp.125-164) schlatter@profsc.fsl.noaa.gov 1981, http://www.cdc.noaa.gov/coads/software/other/profs

Threlkeld, J.L., 1970. Thermal Environmental Engineering, $2^{\text {nd }}$ edtn., Prentice-Hall,; see also Keuhn, T.H., et al, 1998, $3^{\text {rd }}$ edtn.

Young, J.B., 1988. "An equation of state for steam for turbomachinery and other flow calulations," $A S M E$ $J$ Engineering for Gas Turbines \& Power, 110:1-7 
Table D-1. Moist Air Subroutine Listing.

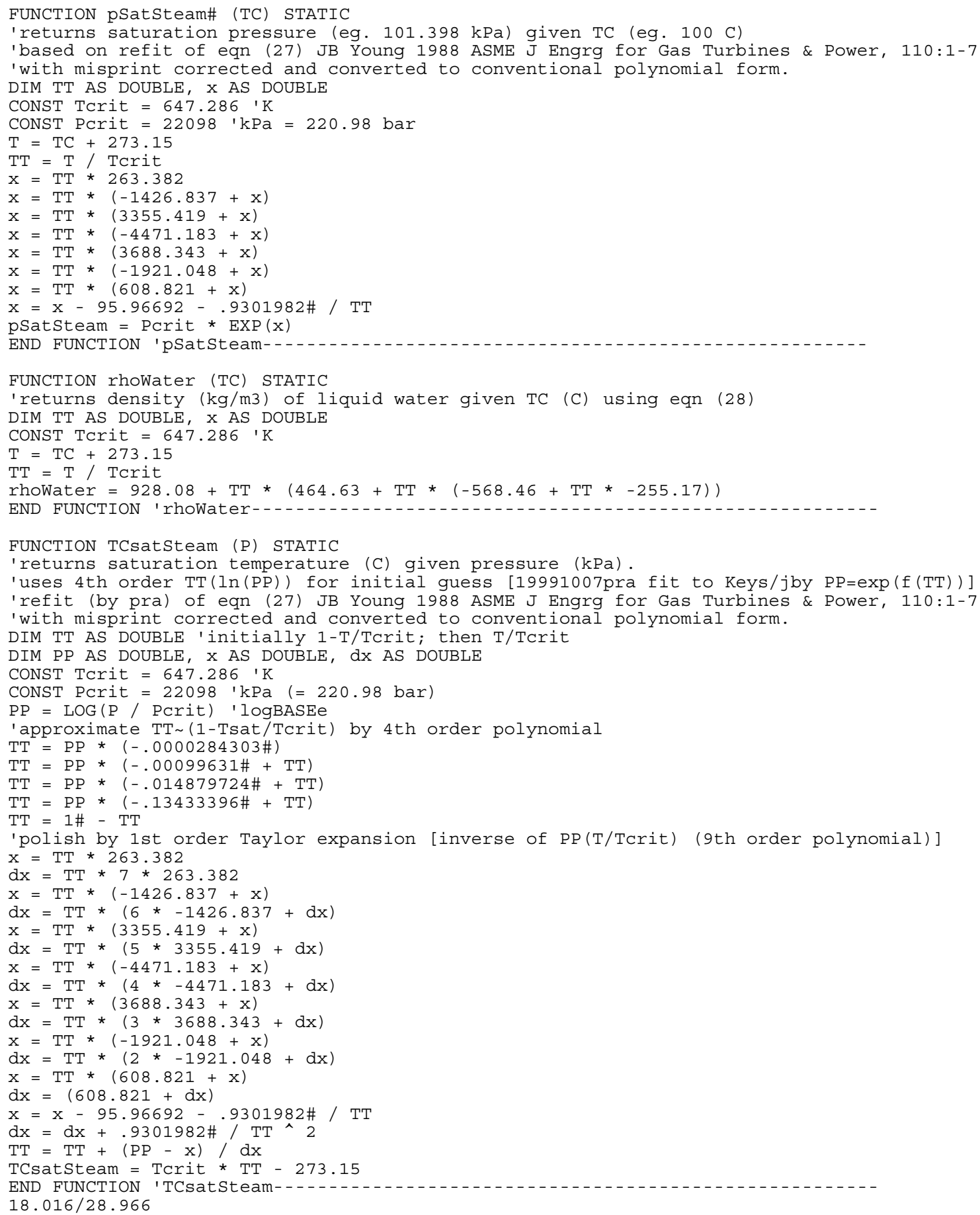




\section{Appendix E. Sensor List}

\begin{tabular}{|c|c|c|c|c|c|c|c|c|}
\hline$I^{(a)}$ & Point Description & $\begin{array}{l}\text { Input } \\
(b)\end{array}$ & $\begin{array}{l}\text { Sensor } \\
\text { Range }\end{array}$ & $\begin{array}{l}\text { Normal } \\
\text { Range }\end{array}$ & $\underset{(c)}{U_{(c)}}$ & Sensor Type & $\begin{array}{c}\text { Sensor } \\
\text { Manufacture }\end{array}$ & $\begin{array}{c}\text { Sensor } \\
\text { Model }\end{array}$ \\
\hline T0 & TC reference & SE & $-250: 370$ & $10: 30$ & ${ }^{\circ} \mathrm{C}$ & Thermistor & CampbellSci & 107 \\
\hline T1 & Return air & SE & $-250: 370$ & $15: 30$ & ${ }^{\circ} \mathrm{C}$ & ermocouple, type & CS Gordon & T24-1-505 \\
\hline T2 & Mixed air & SE & $-250: 370$ & $10: 30$ & ${ }^{\circ} \mathrm{C}$ & & CS Gordon & T24-1-505 \\
\hline T3 & Supply air & SE & $-250: 370$ & $10: 30$ & ${ }^{\circ} \mathrm{C}$ & & CS Gordon & T24-1-505 \\
\hline T4 & Stage1 suction & SE & $-250: 370$ & $10: 25$ & ${ }^{\circ} \mathrm{C}$ & & CS Gordon & T24-1- \\
\hline T5 & Stage1 liquid into TXV & SE & $-250: 370$ & 20:35 & ${ }^{\circ} \mathrm{C}$ & Thermocouple, type & $\mathrm{CS} \mathrm{Gc}$ & 505 \\
\hline T6 & Stage1 discharge & SE & $-250: 370$ & $30: 70$ & ${ }^{\circ} \mathrm{C}$ & Thermocouple, type & CS Gordon & T24-1-505 \\
\hline T4 & Stage2 suction & SE & $-250: 370$ & $10: 25$ & ${ }^{\circ} \mathrm{C}$ & pe & CS Gordon & T24-1-505 \\
\hline T5 & Stage2 liquid in & SE & $-250: 370$ & $20: 35$ & ${ }^{\circ} \mathrm{C}$ & & CS G & T24- \\
\hline T6 & Stage & SE & -250 & $30: 70$ & ${ }^{\circ} \mathrm{C}$ & Thermocouple, type & CS Go & T24-1 \\
\hline DT1 & Eva & SE & -100 & & ${ }^{\circ} \mathrm{C}$ & thermopile, type $T$ & CS Gor & T24. \\
\hline $\mathrm{H} 1$ & $\mathrm{RH}$ mixed air & SE & $0: 100$ & $40: 70$ & \multicolumn{3}{|c|}{ \%RH dielectric polymer filmHyCal } & $\mathrm{IH}-36$ \\
\hline $\mathrm{H} 2$ & RH supply air & SE & $0: 100$ & $40: 99$ & \multicolumn{3}{|c|}{$\% \mathrm{RH}$ dielectric polymer filmHyCal } & IH-3610-1 \\
\hline V1 & Evaporator face veloc. & SE & $0: 420$ & $0: 300$ & \multicolumn{3}{|c|}{ sfpm thermo-anemometer Sierra } & 600L06PV1 \\
\hline P1 & Stage1 cmpr. suction & SE & & $0: 100$ & \multicolumn{3}{|c|}{ psig strain gage on silicon $\mathrm{JCl}$} & P399 \\
\hline P2 & Stage $2 \mathrm{cr}$ & SE & 175:195 & $0: 485$ & \multicolumn{3}{|c|}{ psig strain gage on silicon $\mathrm{JCl}$} & P399 \\
\hline P3 & Stage1 cmpr. suction & SE & $95: 105$ & $0: 100$ & \multicolumn{3}{|c|}{ psig strain gage on silicon $\mathrm{JCl}$} & P399 \\
\hline P4 & Stage2 cmpr. dischg. & SE & $175: 195$ & $0: 485$ & \multicolumn{3}{|c|}{ psig strain gage on silicon $\mathrm{JCl}$} & P399 \\
\hline P5 & Barometer & SE & $800: 11005$ & 970:1030 & & & & 207 \\
\hline P6 & Fan inlet velocity head & SE & $0: 0.5$ & $0: 0.2$ & \multicolumn{3}{|c|}{ inwc strain gage on silicon MAMAC } & PR-274 \\
\hline F1 & Sump to EER+ & $P$ & $0: 10$ & $0: 5$ & \multicolumn{2}{|c|}{ gpm tipping bucket } & Rainwise & \\
\hline $\mathrm{F} 2$ & Sump Overflow & $P$ & $0: 10$ & $0: 0$ & \multicolumn{2}{|c|}{ gpm tipping bucket } & Rainwise & \\
\hline E1 & Compressors & $P$ & $0: 20$ & $0: 8$ & \multicolumn{2}{|c|}{ kW electronic 3- $\varphi$ meter } & Davidge & $4010,4270 / 3$ \\
\hline E2 & Condenser fans & $\mathrm{P}$ & $0: 5$ & $0: 1$ & \multicolumn{2}{|c|}{ kW electronic 1- $\varphi$ meter } & Davidge & $4020,4270 / 2$ \\
\hline E3 & Sump pumps & $\mathrm{P}$ & $0: 5$ & $0: 0.1$ & \multirow{2}{*}{\multicolumn{2}{|c|}{$\mathrm{kW}$ electronic 1- $\varphi$ meter }} & Davidge & $4020,4270 /$ \\
\hline E4 & Total at breaker & (d) & $0: 20$ & $0: 10$ & & & Synergistic & C180E \\
\hline
\end{tabular}

(a) $\mathrm{T}=$ =temperature, $\mathrm{DT}=$ differential $\mathrm{T}, \mathrm{H}=$ =humidity, $\mathrm{V}=$ =mass velocity, $\mathrm{E}=$ power or heat rate, $\mathrm{F}=$ flow rate

(b) $\mathrm{DE}=$ differential, $\mathrm{SE}=$ single-ended, $\mathrm{P}=$ pulse count, IN=integrated $\mathrm{ON}$-time

(c) ${ }^{\circ} \mathrm{C}=$ degree Centigrade, pps=pulse per second, $\% \mathrm{RH}=$ percent relative humidity, $\mathrm{mB}=$ =millibar, inWC=inch water column, $\mathrm{mV}=$ millivolt, $\mathrm{kW}=$ kilowatt, $\mathrm{kWh}=$ kilowatt hour, $\mathrm{sfps}=$ standard feet per second, acfm/scfm=actual/standard $\mathrm{ft}^{3}$ per minute, s=second; all units apply to both the Sensor Range and Normal Range columns.

(d) Three-phase line voltage and the outputs of 3 Magnetek 50-amp CTs are sampled by a Synergistic C180E logger to compute real and reactive power; the $\mathrm{C} 180$ is polled separately from the CR10X and the two data streams are 


\section{Appendix F. Photo Documentation of Monitoring and RTU Equipment}

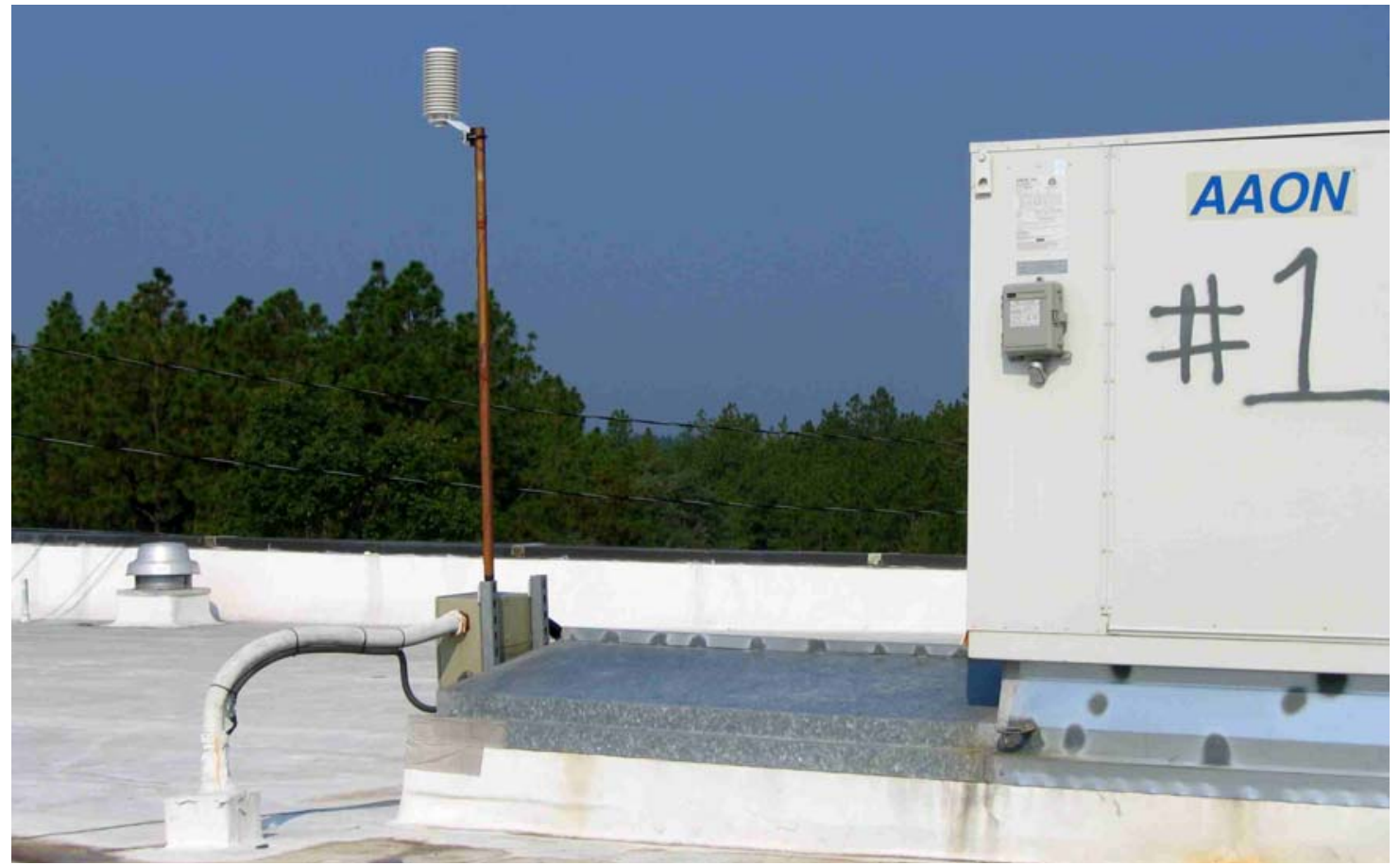

Figure F-1. Mast and radiation shield for outdoor air temperature sensor.

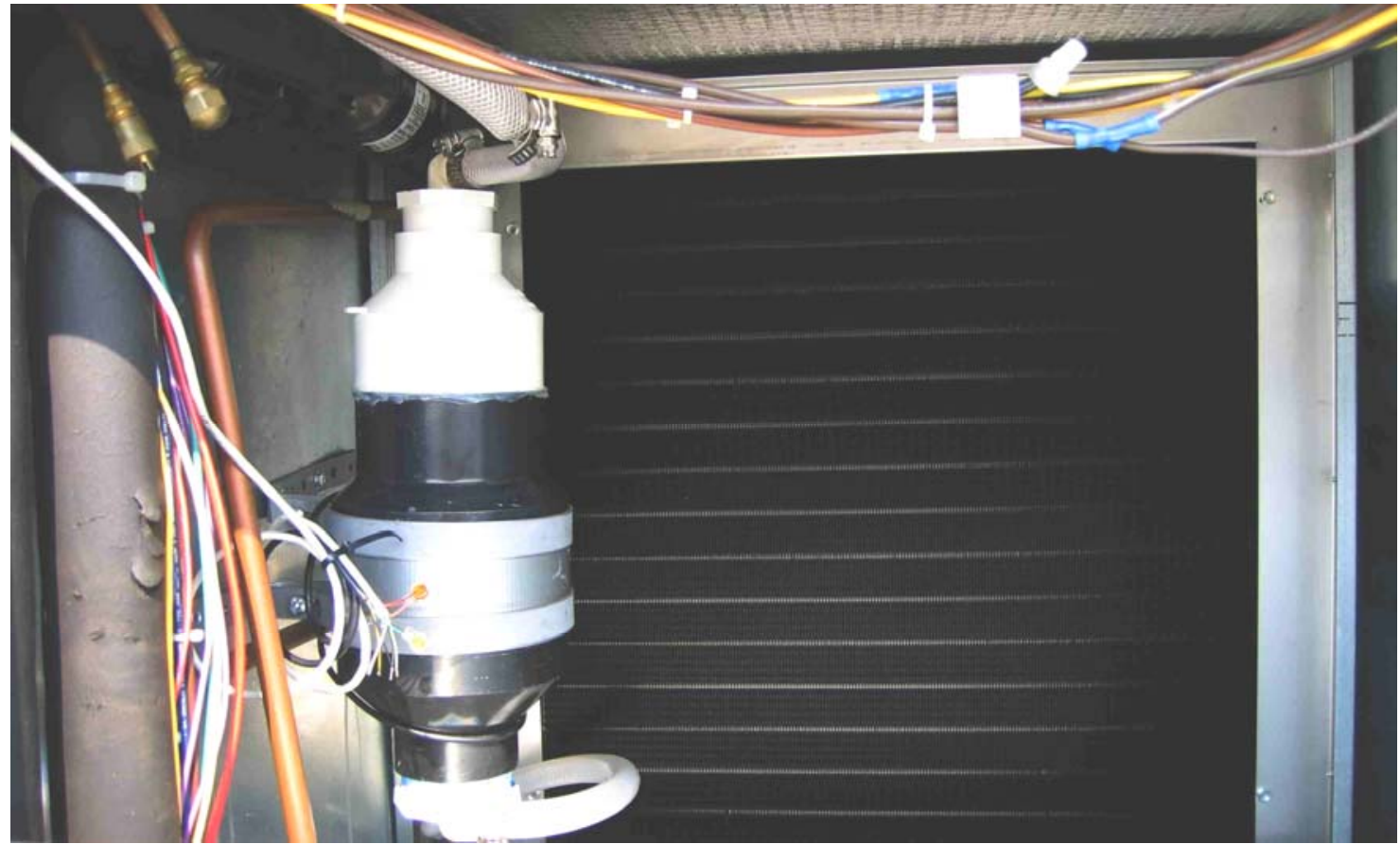

Figure F-2. EER+ compartment from discharge side. Shown, from the left, are insulated suction line, discharge line (right angle bend at top takes it back to the desuperheater, discharge face of which fills most of the background), and condensate flow meter (tipping bucket enclosed in the vertical assembly of PVCABS-PVC fittings). Liquid line service ports for circuits A and B are visible in the upper left. This photo was taken before the installation of suction, discharge, and liquid line temperature sensors. 


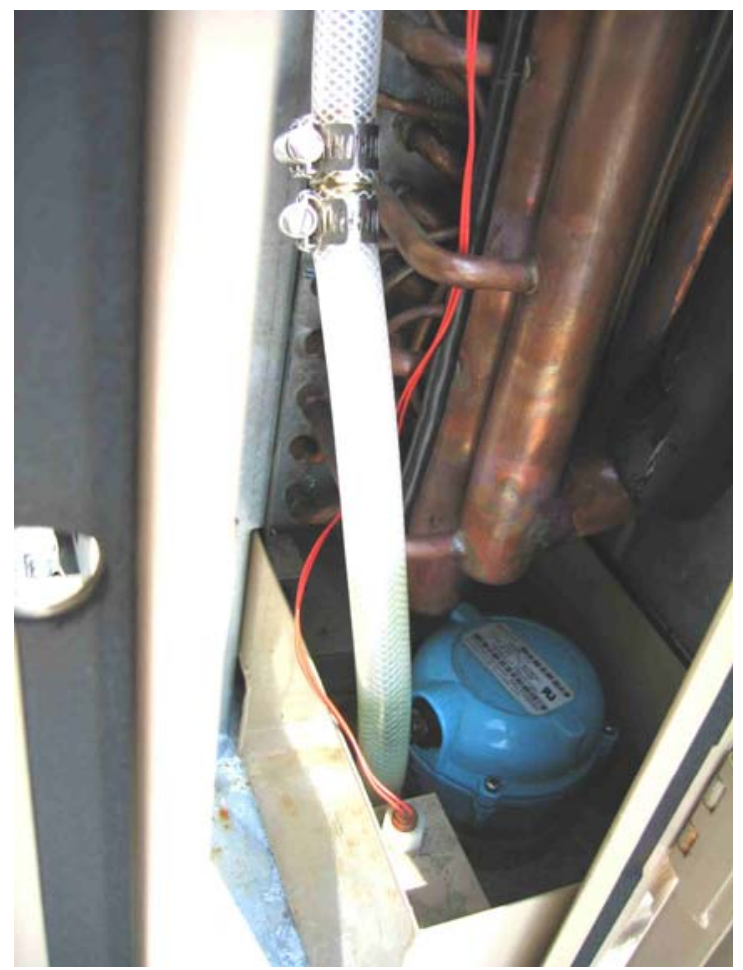

Figure F-4. Control panel showing power submeter components: two red compressor CTs in lower right connect to the three-phase EZ-meter module on the far right. A black CT in lower left picks up condenser fan power and another black CT in upper right picks up EER+ (small fan and two pumps) power. The black CTs connect to the twochannel single-phase EZ-meter module partially hidden by opto-isolator module at extreme upper right.
Figure F-3 (left). Evaporator, sump pump, and float switch. Float switch and pump intake screen are potential maintenance items.

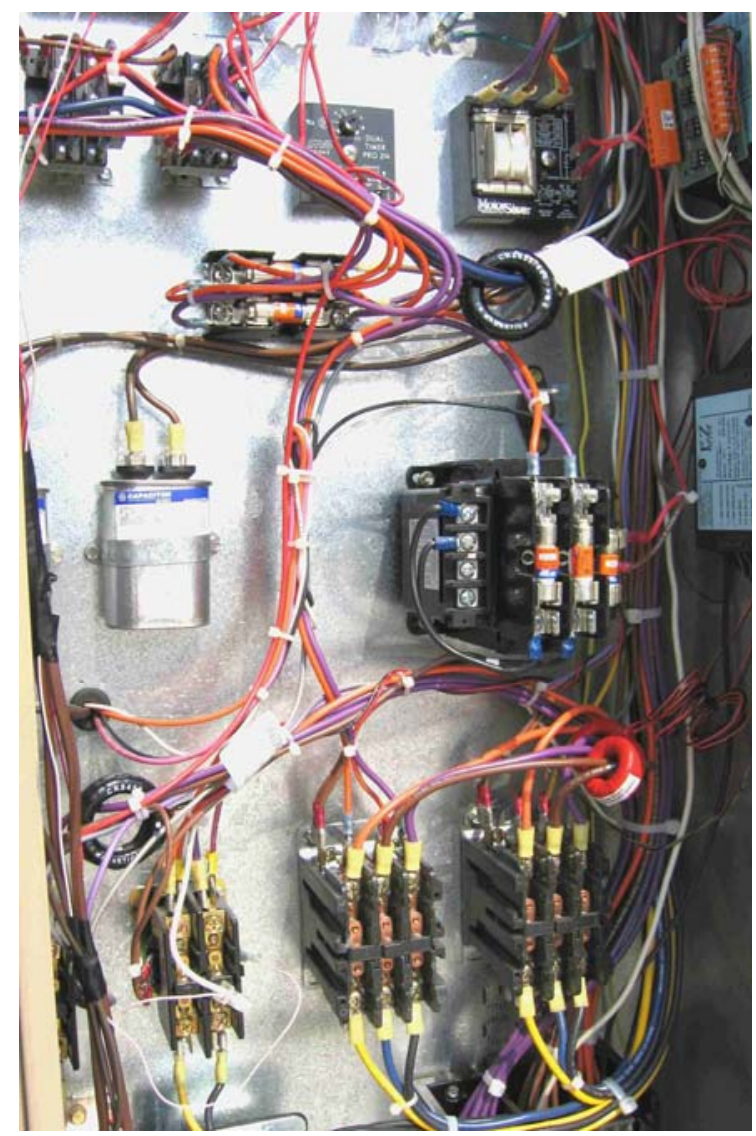




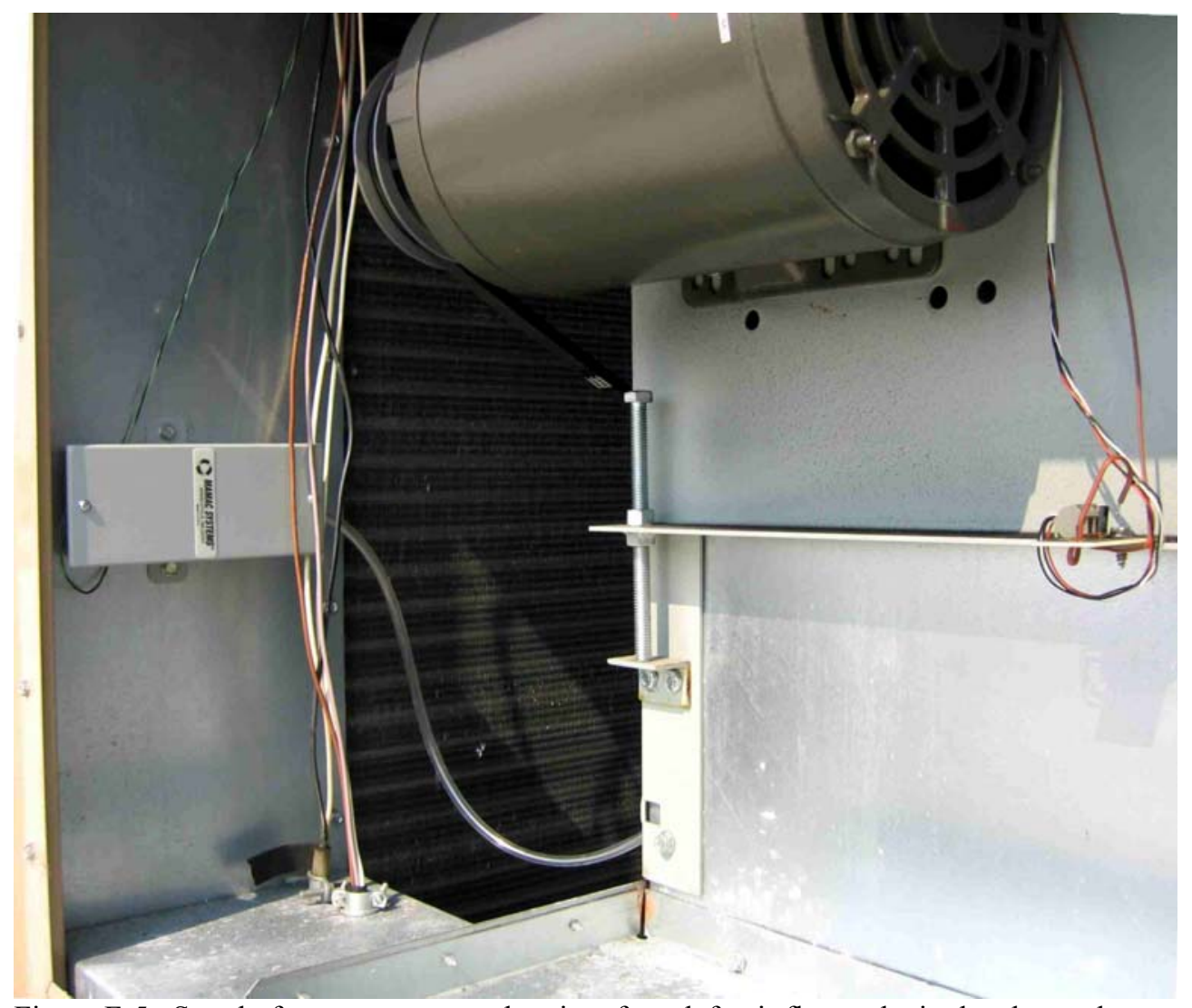

Figure F-5. Supply fan compartment showing, from left: air flow velocity head transducer, evaporator discharge face, supply fan. The supply air RH sensor and thermocouple are attached to the fan motor subframe at far right.

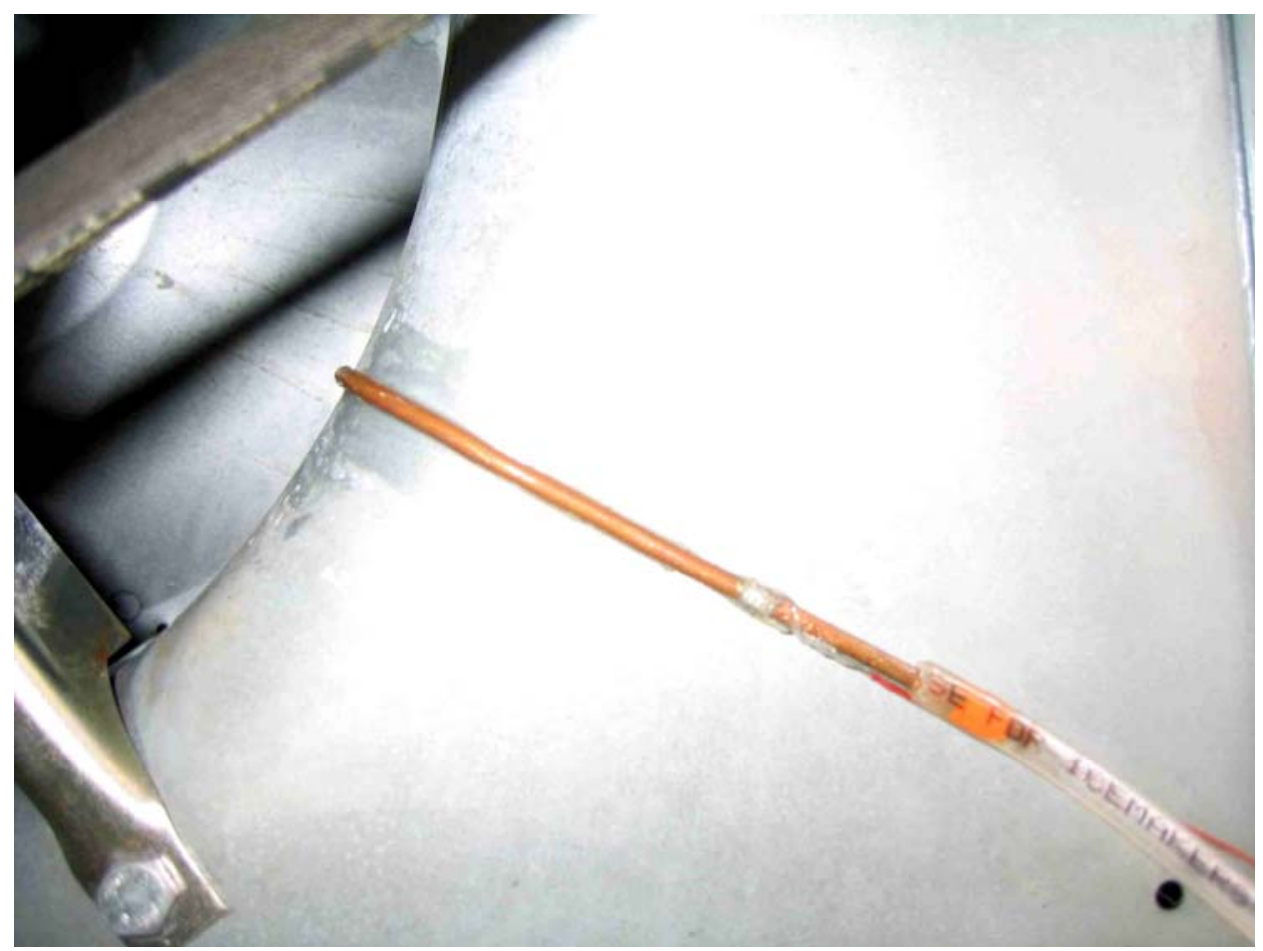

Figure F-6. View of supply fan inlet bell showing the throat pressure tap. 


\section{Appendix G. Regression of Application EER versus $\mathbf{T}_{\mathrm{ODB}}$ and $\mathbf{T}_{\mathrm{EWB}}$ -}

The EER is modeled as a linear function of outdoor dry-bulb temperature, $\mathrm{T}_{\mathrm{ODB}}$, and entering wet-bulb temperature, $\mathrm{T}_{\mathrm{EWB}}$. The latter refers to air entering the cooling coil, also known as mixed-air temperature. This model is expressed mathematically by:

$$
\mathrm{EER}=\mathrm{c}_{0}+\mathrm{c}_{1} \mathrm{~T}_{\mathrm{ODB}}+\mathrm{c}_{2} \mathrm{~T}_{\mathrm{EWB}}
$$

where $\mathrm{c}_{0}, \mathrm{c}_{1}$, and $\mathrm{c}_{2}$ are coefficients from the regressions. The coefficients and their t-ratios are reported in Tables G-1 through G-4. The t-ratio is given by:

$$
\text { t-ratio }=|\operatorname{coeff}| / \operatorname{se}(\text { coeff })
$$

where se(coeff) is the standard error of the coefficient, which is obtained from the diagonal of the covariance matrix. The covariance matrix is evaluated during the linear least squares calculation. A given model coefficient is considered statistically significant when its t-ratio is greater than 2 . The standard error of the EER prediction, se(EER), is also given for each application of eqn (1). Note that se(EER) is larger for RTU 4 than RTU 1; about 20\% larger for stage- 1 observations and about twice as large for stage- 2 observations. Because the EER impact of desuperheating and subcooling is larger in stage-2 than stage- 1 , we postulate that the variation in the return-air RH is probably the source of the larger variance.

Table G-1. Baseline (RTU 1) EER Model, Stage-1 Cooling Data, se(EER)=0.132.

\begin{tabular}{|c|c|cc|}
\hline Term & Units & Coeff. & t-ratio \\
\hline Constant & Btu/Wh & 4.378 & 170.2 \\
$\mathrm{~T}_{\mathrm{ODB}}$ & ${ }^{\circ} \mathrm{F}$ & -0.05566 & 301.8 \\
$\mathrm{~T}_{\mathrm{EWB}}$ & ${ }^{\circ} \mathrm{F}$ & 0.1092 & 272.6 \\
\hline
\end{tabular}

Table G-2. Baseline (RTU 1) EER Model, Stage-2 Cooling Data, se(EER)=0.127.

\begin{tabular}{|c|c|cc|}
\hline Term & Units & Coeff. & t-ratio \\
\hline Constant & Btu/Wh & 6.641 & 80.98 \\
$\mathrm{~T}_{\mathrm{ODB}}$ & ${ }^{\circ} \mathrm{F}$ & -0.07891 & 187.1 \\
$\mathrm{~T}_{\mathrm{EWB}}$ & ${ }^{\circ} \mathrm{F}$ & 0.1313 & 113.1 \\
\hline
\end{tabular}

Table G-3. GEG (RTU 4) EER Model, Stage-1 Cooling Data, se(EER)=0.160.

\begin{tabular}{|c|c|cc|}
\hline Term & Units & Coeff. & t-ratio \\
\hline Constant & Btu/Wh & 3.764 & 66.79 \\
$\mathrm{~T}_{\mathrm{ODB}}$ & ${ }^{\circ} \mathrm{F}$ & -0.05297 & 267.4 \\
$\mathrm{~T}_{\mathrm{EWB}}$ & ${ }^{\circ} \mathrm{F}$ & 0.1523 & 178.7 \\
\hline
\end{tabular}

Table G-4. GEG (RTU 4) EER Model, Stage-2 Cooling Data, se(EER)=0.278.

\begin{tabular}{|cc|cc|}
\hline Term & Units & Coeff. & t-ratio \\
\hline Constant & Btu/Wh & 11.12 & 35.99 \\
$\mathrm{~T}_{\mathrm{ODB}}$ & ${ }^{\circ} \mathrm{F}$ & -0.07511 & 80.42 \\
$\mathrm{~T}_{\mathrm{EWB}}$ & ${ }^{\circ} \mathrm{F}$ & 0.09697 & 22.35 \\
\hline
\end{tabular}

To provide a rational basis for comparison, the EER observations need to be normalized for specific fan power $^{22}$. In this case the supply fan of RTU 1 is being operated at a much higher specific fan power than

\footnotetext{
${ }^{22}$ Specific fan power is defined as supply fan power measured in a given application divided by ARI capacity. It is determined mainly by the cfm (selected by the designer or installer) and the external static pressure. Manufacturers offer two or three motor options to accommodate a range of application-specific
} 
the supply fan of RTU $4\left(\mathrm{SP}_{\mathrm{RTU} 1}=264 \mathrm{~W} /\right.$ ton versus $\mathrm{SP}_{\mathrm{RTU} 4}=110 \mathrm{~W} /$ ton $) . \quad$ Consider the EER of $\mathrm{RTU} 1$ expressed as if it had no supply fan, i.e., as a standalone compressor-condenser unit would be rated:

$$
E E R_{C C 1}=\frac{Q_{R T U 1}}{P_{R T U 1}-F P_{R T U 1}}
$$

where $Q_{R T U I}$ is the cooling output in Btu/h, $P_{R T U I}$ is the input power in watts measured at the RTU supply circuit (Figure 7), and $F P_{R T U I}$ is the average supply fan power of RTU 1.

The normalized EER is obtained by simply adding the fan power of RTU 4, $F P_{R T U 4}$, appropriately scaled, back into the denominator as follows:

$$
E E R_{a d j 1}=\frac{Q_{R T U 1}}{P_{R T U 1}-F P_{R T U 1}+x F P_{R T U 14}}
$$

where

$x=236 \mathrm{kBtuh}) /(115 \mathrm{kBtuh})$ is the ratio of RTU 1 capacity to RTU 4 capacity.

Running least squares on the normalized EER data, $\mathrm{EER}_{\mathrm{adj} 1}\left(\mathrm{~T}_{\mathrm{ODB}}, \mathrm{T}_{\mathrm{EWB}}\right)$, produces the linear models (coefficients of equation 1) presented in Tables G-5 and G-6.

Table G-5. Normalized Fan Baseline Model, Stage-1 Cooling Data, se(EER)=0.172.

\begin{tabular}{|c|c|rc|}
\hline Term & Units & Coeff. & t-ratio \\
\hline Constant & Btu/Wh & 6.380 & 192.8 \\
$\mathrm{~T}_{\mathrm{ODB}}$ & ${ }^{\circ} \mathrm{F}$ & -0.0774 & 326.2 \\
$\mathrm{~T}_{\text {EWB }}$ & ${ }^{\circ} \mathrm{F}$ & 0.1315 & 255.2 \\
\hline
\end{tabular}

Table G-6. Normalized Fan Baseline Model, Stage-2 Cooling Data, se(EER)=0.152.

\begin{tabular}{|c|c|cc|}
\hline Term & Units & Coeff. & t-ratio \\
\hline Constant & Btu/Wh & 8.603 & 88.3 \\
$\mathrm{~T}_{\mathrm{ODB}}$ & ${ }^{\circ} \mathrm{F}$ & -0.0983 & 196.3 \\
$\mathrm{~T}_{\mathrm{EWB}}$ & ${ }^{\circ} \mathrm{F}$ & 0.1454 & 105.5 \\
\hline
\end{tabular}

The application EERs at ARI standard (full-load) rating conditions $\left(\mathrm{T}_{\mathrm{ODB}}=95^{\circ} \mathrm{F}, \mathrm{T}_{\mathrm{EWB}}=67^{\circ} \mathrm{F}\right)$ and at $\mathrm{ARI}$ part-load conditions $\left(\mathrm{T}_{\mathrm{ODB}}=80^{\circ} \mathrm{F}, \mathrm{T}_{\mathrm{EWB}}=67^{\circ} \mathrm{F}\right)$ are estimated by evaluating equation (1) at said conditions, e.g. at ARI full-load conditions, $\mathrm{EER}_{\mathrm{ARI}}=\mathrm{c}_{0}+95 \mathrm{c}_{1}+67 \mathrm{c}_{2}$. These results are summarized in Table G-7.

$\mathrm{cfm}$ and ESP requirements. One indication that RTU1 is running near the upper limit of its specific fan power range is that it contains the largest of the three motor options offered in the AAON catalog. 
Table G-7. Application EER from Measured Performance Data

\begin{tabular}{|c|c|c|c|}
\hline & \multicolumn{2}{|c|}{$\begin{array}{c}\text { Application EER } \\
\text { (Btu/Wh) }\end{array}$} \\
\hline & & full-load & part load \\
\hline RTU 1 EER & stage-1 & 6.41 & 7.24 \\
\hline RTU 1 EER & stage-2 & 7.94 & 9.13 \\
\hline RTU 4 EER & stage-1 & 8.94 & 9.73 \\
\hline RTU 4 EER & stage-2 & 10.48 & 11.61 \\
\hline RTU 1 EER ${ }_{\text {adj }}$ & stage-1 & 7.84 & 9.00 \\
\hline RTU 1 EER & stage-2 & 9.00 & 10.48 \\
\hline
\end{tabular}

We use four models, designated RTU 1 EER $_{\text {adj }}$ stage-1, RTU 1 EER $_{\text {adj }}$ stage-2, RTU 4 EER stage-1, and RTU 4 EER stage-2 (from Tables G-3, G-4, G-5 and G-6), to estimate annual energy requirements of the two types of package cooling equipment by the bin method as described in Appendix I. 


\section{Appendix H. ARI 340/360 Rating Test Conditions}

The table below is reproduced from ARI Standard 340/360 (ARI 2000).

\begin{tabular}{|c|c|c|c|c|c|c|c|c|c|}
\hline \multirow{4}{*}{\multicolumn{2}{|c|}{ TEST }} & \multirow{2}{*}{\multicolumn{2}{|c|}{$\begin{array}{l}\text { DNDOOR UNIT } \\
\text { Air En:aring }\end{array}$}} & \multicolumn{6}{|c|}{ OUTDOOR UNTI } \\
\hline & & & & & Air E: & torieg & & $\mathrm{W}_{2}$ & \\
\hline & & \multirow[b]{2}{*}{$\begin{array}{l}\text { Dry } \\
\text { Bulb } \\
\text { F } \\
{[\mathrm{C}]}\end{array}$} & \multirow[b]{2}{*}{$\begin{array}{l}\text { Wot- } \\
\text { Bulb } \\
\text { F } \\
{[C]}\end{array}$} & \multicolumn{2}{|c|}{ Air Coolad } & \multicolumn{2}{|c|}{ Evzrontine } & \multirow[b]{2}{*}{$\begin{array}{l}\mathrm{DN} \\
\mathrm{F} \\
\mathrm{rCl}\end{array}$} & \multirow[b]{2}{*}{$\begin{array}{c}\text { OUT } \\
\qquad \mathrm{F} \\
\mathrm{C} C]\end{array}$} \\
\hline & & & & $\begin{array}{l}\text { Dry } \\
\mathrm{Br}: \mathrm{b} \\
\mathrm{F} \\
{[\mathrm{C}]}\end{array}$ & $\begin{array}{l}\text { Wat- } \\
\text { Bulb } \\
\text { "F } \\
\mathrm{reC}\end{array}$ & $\begin{array}{l}\text { Dry } \\
\text { Bulb } \\
\text { F } \\
{[C]}\end{array}$ & $\begin{array}{l}\text { Wat- } \\
\mathrm{B}:: 3 \\
\mathrm{~F} \\
{[\mathrm{C}]}\end{array}$ & & \\
\hline \multirow{6}{*}{$\frac{\stackrel{2}{z}}{8}$} & $\begin{array}{l}\text { Stzodard Rating Coeditions } \\
\text { Cooling }\end{array}$ & $\begin{array}{l}020 \\
{[267]}\end{array}$ & $\begin{array}{r}67.0 \\
{[19.4]} \\
\end{array}$ & $\begin{array}{c}95.0 \\
{[35.0]}\end{array}$ & $\begin{array}{l}75.0^{1} \\
{[23.9]}\end{array}$ & $\begin{array}{l}950 \\
{[350]}\end{array}$ & $\begin{array}{c}75.0 \\
{[23.9]} \\
\end{array}$ & $\begin{array}{l}85.0 \\
{[29.4]}\end{array}$ & $\begin{array}{c}95.0 \\
{[35.0]}\end{array}$ \\
\hline & $\begin{array}{l}\text { Low Tomperature Oparating } \\
\text { Cooling }\end{array}$ & $\begin{array}{r}67.0 \\
{[19.4]} \\
\end{array}$ & $\begin{array}{r}57.0 \\
{[139]} \\
\end{array}$ & $\begin{array}{c}67.0 \\
{[19.4]} \\
\end{array}$ & $\begin{array}{l}57.0^{1} \\
{[13.9]} \\
\end{array}$ & $\begin{array}{l}67.0 \\
{[19.4]} \\
\end{array}$ & $\begin{array}{r}57.0 \\
{[13.9]} \\
\end{array}$ & - & $\begin{array}{l}70.0^{ \pm} \\
{[21.11}\end{array}$ \\
\hline & Mavimm Opsentig Cenditicns $^{4}$ & $\begin{array}{r}020 \\
{[267} \\
\end{array}$ & $\begin{array}{c}67.0 \\
{[19.4]} \\
\end{array}$ & $\begin{array}{c}115 \\
{[46.1]}\end{array}$ & $\begin{array}{l}75.0^{1} \\
{[23.9]} \\
\end{array}$ & $\begin{array}{c}100 \\
{[37.8]}\end{array}$ & $\begin{array}{l}80.0^{3} \\
226.7]\end{array}$ & $\begin{array}{l}90.0^{ \pm} \\
{[32.2]}\end{array}$ & - \\
\hline & Pet-Load Cocditioes (IPLV $)^{4}$ & $\begin{array}{l}020 \\
{[267}\end{array}$ & $\begin{array}{c}67.0 \\
{[19.4]}\end{array}$ & $\begin{array}{c}80.0 \\
{[26.7]} \\
\end{array}$ & $\begin{array}{l}67.0^{1} \\
{[19.4]}\end{array}$ & $\begin{array}{c}900 \\
267\end{array}$ & $\begin{array}{c}67.0 \\
{[19.4]}\end{array}$ & $\begin{array}{l}75.0^{ \pm} \\
23.9]\end{array}$ & - \\
\hline & Insulasion Efficiency & $\begin{array}{l}02.0 \\
{[26.7} \\
\end{array}$ & $\begin{array}{r}75.0 \\
{[239]} \\
\end{array}$ & $\begin{array}{c}80.0 \\
{[26.7]} \\
\end{array}$ & $\begin{array}{l}75.0^{1} \\
{[23.9} \\
\end{array}$ & $\begin{array}{c}900 \\
2677 \\
\end{array}$ & $\begin{array}{r}75.0 \\
{[23.9]} \\
\end{array}$ & - & $\begin{array}{r}50.0 \\
26.7 \\
\end{array}$ \\
\hline & Condencste Disposz' & $\begin{array}{c}020 \\
{[267}\end{array}$ & $\begin{array}{c}75.0 \\
{[239]}\end{array}$ & $\begin{array}{c}80.0 \\
{[25.7]}\end{array}$ & $\begin{array}{l}75.0^{1} \\
{[23.9]}\end{array}$ & $\begin{array}{c}900 \\
2677\end{array}$ & $\begin{array}{c}75.0 \\
{[23.9]} \\
\end{array}$ & - & $\begin{array}{r}50.0 \\
26.7\end{array}$ \\
\hline \multirow{3}{*}{$\frac{0}{\frac{3}{3}}$} & 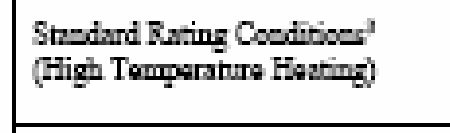 & $\begin{array}{c}70.0 \\
{[21.1]}\end{array}$ & $\begin{array}{r}60.0 \\
(\mathrm{max}) \\
{[15.6]}\end{array}$ & $\begin{array}{c}47 \\
{[8.3]}\end{array}$ & $\begin{array}{c}43 \\
{[6.1]}\end{array}$ & - & - & - & - \\
\hline & $\begin{array}{l}\text { Stzedard Rating Coodicioes' } \\
\text { Low Tomparahure Hevting } \\
\text { (entagratod) }\end{array}$ & $\begin{array}{c}70.0 \\
{[21.1]}\end{array}$ & $\begin{array}{l}60.0 \\
(\operatorname{mox}) \\
{[15.6]}\end{array}$ & $\begin{array}{c}17 \\
{[-8.3]}\end{array}$ & $\begin{array}{c}15 \\
{[-9.4]}\end{array}$ & - & - & - & - \\
\hline & Muximnm Opsratieg Cenditicns & $\begin{array}{r}02.0 \\
{[267} \\
\end{array}$ & - & $\begin{array}{l}75.0 \\
{[23.9]} \\
\end{array}$ & $\begin{array}{c}65.0 \\
{[18.3]} \\
\end{array}$ & - & - & - & - \\
\hline \multicolumn{10}{|c|}{ 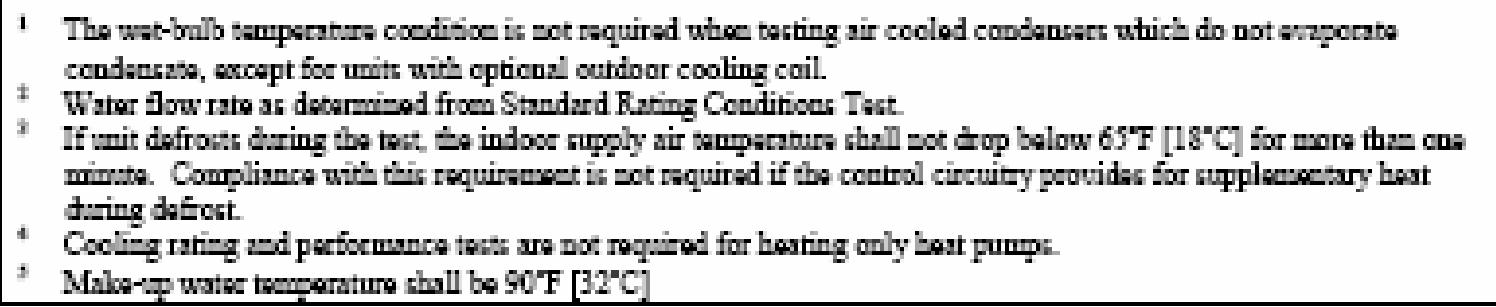 } \\
\hline
\end{tabular}




\section{Appendix I. Energy and Life-Cycle Cost by UAC Cost Estimator}

The UAC cost-estimator was developed for the original procurement effort that motivated this field evaluation. To estimate seasonal performance we must specify, in addition to the performance map described in Appendix G, a climate and a load. To compare the life-cycle costs of two RTUs we must also specify energy prices, cost of money as annual percentage rate (APR), an analysis period, and the initial and annual maintenance costs for the units to be compared.

The load model developed for the UAC cost estimator (www.pnl.goc/uac) and a bin analysis method that uses typical meteorological year (TMY2; Marion 1995) weather data are used to estimate annual energy consumption for a given load and climate. A spreadsheet version of the UAC calculator, shown in Table I1 , was used for this analysis instead of the on-line version of the UAC so that we could plug in the exact baseline and new technology application EER coefficients reported in Tables G-3 through G-6 and to facilitate sensitivity analysis.

The load model assumes a sensible cooling load directly proportional to outdoor temperature and a latent load directly proportional to the product of outdoor humidity (mass ratio of water vapor to dry air) and outside air flow rate. An ideal enthalpy control is assumed and a fixed minimum outside air flow rate ( $10 \%$ in this analysis) is specified by the user. The peak load (for sizing purposes) is assumed to occur at the ASHRAE $0.4 \%$ dry- and wet-bulb temperatures with the minimum $(40 \mathrm{scfm} / \mathrm{Ton})^{23}$ outside air-flow setting. The cooling balance point is assumed to be $50^{\circ} \mathrm{F}$.

After the hourly coil load is evaluated by the load model for a given bin temperature, the $1^{\text {st }}$-and $2^{\text {nd }}$-stage duty fractions are calculated. The duty fractions are adjusted to account for cycling loss. The $1^{\text {st }}-$ and $2^{\text {nd }}-$ stage EER models are then applied to determine average $\mathrm{kW}$ for a bin and this is multiplied by the number of annual bin hours to get bin $\mathrm{kWh}$. The resulting $\mathrm{kWh}$ numbers for each bin are then summed over all bins to get the annual operating energy.

The present value of annual operating energy is plugged into standard LCC formulas to arrive at the comparative net present value (NPV) term. The unit to be replaced is assumed to be at the end of its useful $\operatorname{life}^{24}$. Site-specific energy prices, cost of money as annual percentage rate (APR), an analysis period, and the initial and annual maintenance costs for the units are entered into the spreadsheet. The assumed initial and annual maintenance costs for the baseline unit are $\$ 3824.00$ and $100.00 / \mathrm{yr}$ for all sensitivity NPV calculations The sensitivity of NPV to purchase price, electricity and maintenance costs is shown in Table I-2. The table looks at two values of initial cost ( $\$ 4674.50$ and $\$ 5525.00)$, three values of annual maintenance cost $(112.50,125$, and $150 \$ / \mathrm{yr})$ and three values of effective cost per $\mathrm{kWh}(0.08,0.10$, and $0.12 \$ / \mathrm{kWh}$ ) and reports the net present value for all combinations of these life-cycle cost parameters.

\footnotetext{
${ }^{23} 40 \mathrm{scfm}$ per Ton of cooling capacity corresponds to about $10 \%$ outside air, a typical minimum outside air fraction

${ }^{24}$ The NPV comparisons are also valid for selection of equipment in new construction and replace-onfailure scenarios; replacement of standard-efficiency equipment before the end of its useful life will result in a less attractive NPV.
} 
Table I-1. Spreadsheet Implementation of the UAC Calculator

\section{UAC ENERGY AND LIFE-CYCLE COST CALCULATION}

Location: Augusta, GA

1. Input first stage capacity (or total for single compressor):

2. Input second stage capacity (if applicable):

$115 \mathrm{kBtuh}$

Dry Bulb: $96.8^{\circ} \mathrm{F}$ $76.1^{\circ} \mathrm{F}$

Wet Bulb:
ASHRAE 0.4\% Design Conditions Capacity:

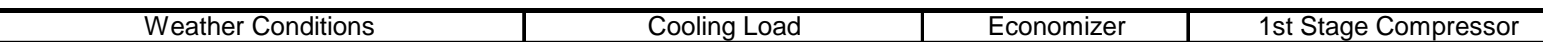

Total Annual Energy Use

Baseline Alternative

AAON PH010C

Equipment cost (\$) $\quad 3824.00 \quad 5525.00$

Maintenance $(\$ / y r)$

$\mathrm{PW}(\mathrm{mtnc})(\$)$

$\begin{array}{lll}\mathrm{PW} \text { (energy) (\$) } & 29893.65 & 27599.17\end{array}$

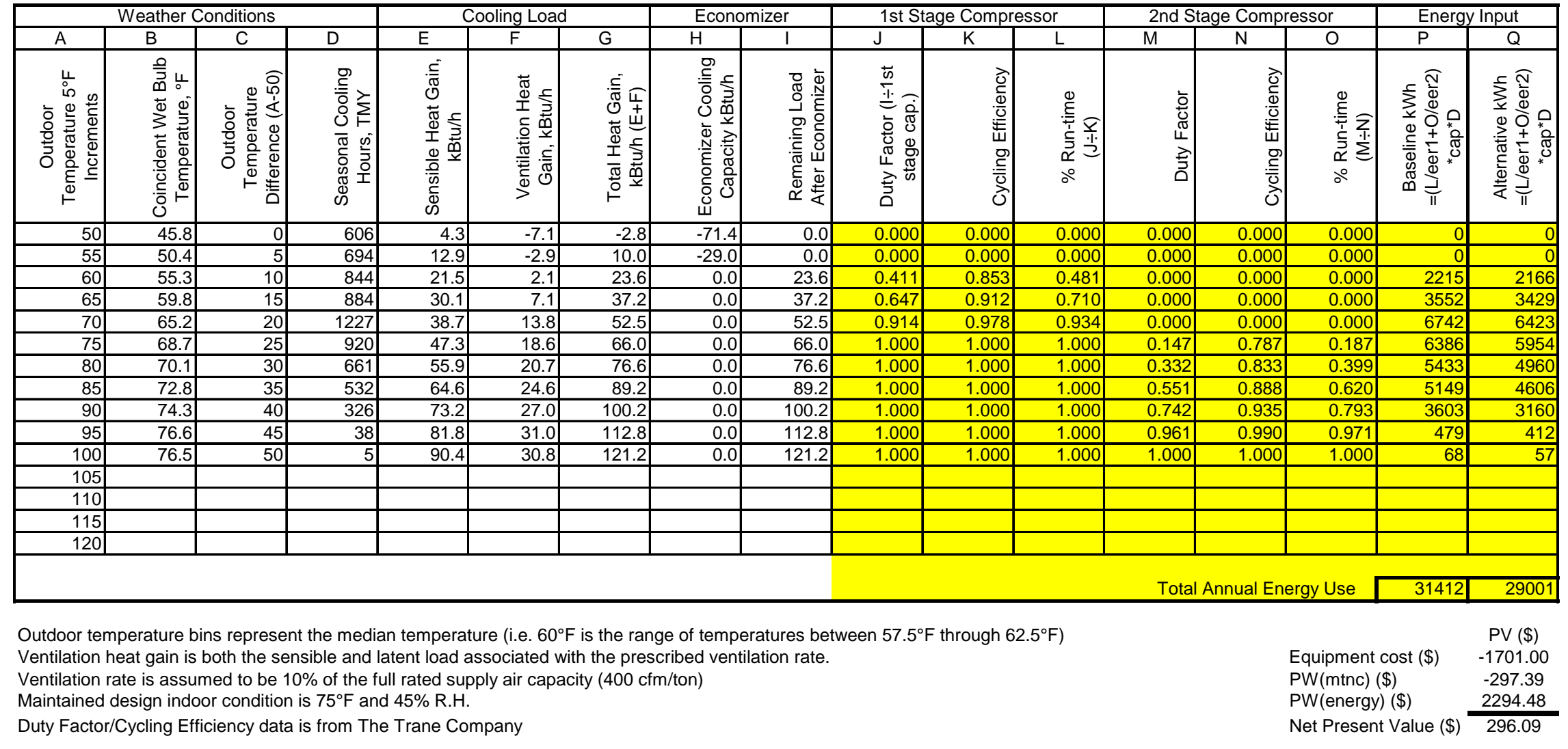


Table I-2. Sensitivity of NPV with respect to Purchase and Maintenance Costs and Electricity Price.

\begin{tabular}{|c|c|c|c|c|c|c|c|c|c|c|c|c|c|c|c|c|c|c|}
\hline \multirow{4}{*}{\begin{tabular}{|l} 
Cost Element \\
Purchase $(\$)$ \\
Maintenance (\$/yr) \\
\end{tabular}} & \multicolumn{18}{|c|}{ Net Present Values (NPV) of Energy-Efficient versus Baseline RTU for hypothetical building with 10-ton design load in selected climates } \\
\hline & \multicolumn{9}{|c|}{4674.50} & \multicolumn{9}{|c|}{5525.00} \\
\hline & \multicolumn{3}{|c|}{112.50} & \multicolumn{3}{|c|}{125.00} & \multicolumn{3}{|c|}{150.00} & \multicolumn{3}{|c|}{112.50} & \multicolumn{3}{|c|}{125.00} & \multicolumn{3}{|c|}{150.00} \\
\hline & .08 & 0.10 & 0.12 & 0.08 & 0.10 & 0.12 & 0.08 & 0.10 & 0.12 & 0.08 & 0.10 & 0.12 & 0.08 & 0.10 & 0.12 & 0.08 & 0.10 & 0.12 \\
\hline Atlanta, GA & 501 & 877 & 1252 & 352 & 727 & 1103 & 54 & 429 & 804 & -354 & 20 & 394 & -503 & -129 & 245 & -800 & -426 & -52 \\
\hline Augusta, GA & 1303 & 1879 & 2454 & 1154 & 1729 & 2305 & 855 & 1431 & 2007 & 445 & 1018 & 1592 & 296 & 870 & 1443 & -1 & 572 & 1146 \\
\hline Chicago, IL & 70 & 337 & 605 & -79 & 188 & 455 & -378 & -111 & 157 & -784 & -518 & -251 & -933 & -666 & -400 & -1230 & -964 & -697 \\
\hline Denver, CO & -51 & 186 & 424 & -200 & 37 & 274 & -498 & -261 & -24 & -904 & -668 & -431 & -1053 & -816 & -580 & -1350 & -1114 & -877 \\
\hline Phoenix, AZ & 2145 & 2932 & 3718 & 1996 & 2782 & 3569 & 1698 & 2484 & 3270 & 1284 & 2068 & 2851 & 1135 & 1919 & 2702 & 838 & 1621 & 2405 \\
\hline San Francisco, CA & -533 & -417 & -300 & -683 & -566 & -449 & -981 & -864 & -748 & -1385 & -1269 & -1153 & -1534 & -1417 & -1301 & -1831 & -1715 & -1599 \\
\hline Seattle, WA & -586 & -483 & -379 & -735 & -632 & -529 & -1034 & -930 & -827 & -1438 & -1335 & -1232 & -1586 & -1483 & -1380 & -1884 & -1781 & -1678 \\
\hline Baltimore, MD & 251 & 564 & 876 & 102 & 414 & 727 & -197 & 116 & 429 & -604 & -292 & 19 & -752 & -441 & -129 & -1050 & -738 & -427 \\
\hline
\end{tabular}




\section{Appendix J. Issues in Measurement of Package A/C Field Performance}

The art of measuring thermal performance in the field is a challenging one and a retrospective assessment shows that even with several iterations within this single package equipment monitoring project we have not achieved anything like the kind of accuracy (1\%) we have come to expect from electrical end-use metering. The reasons for this, and some possible ways to move towards better monitoring protocols and greater accuracy, are outlined in this appendix.

Specific Fan Power Issue. Equipment sizing is an important factor in long-term performance. However, it is easy to forget that choice of supply-air flow rate, both a design and commissioning issue, can easily overshadow proper sizing and EER rating in determining the annual energy use. We estimate that even in long cooling season situations, 50-hours per week (the minimum number of occupied hours for most commercial buildings) fan operation will generally result in an annual fan energy use that is larger than the annual compressor energy use.

External static pressure (ESP) is another important factor that is, again, both a design and commissioning issue. Even if the distribution system is originally designed for low pressure drop, improper damper setting (and user blockage of registers), as well as kinked flex ducts, can result in ESP creeping up (or down) over time. Most sites keep a log of maintenance by unit. A record of ESP, measured during spring maintenance, would be useful. Reference to past values can alert the maintenance worker of the need for corrective action at the time of measurement so that it is possible to correct the problem without making another trip to the building in question.

Recommended Fan Normalization Protocol. The difference in specific fan power should be assessed and, to the extent possible, corrected at the outset. (The finer points may be debated, but...). At the least, one should adjust the sheaves on one or both fans until specific flow rates $(\mathrm{cfm})$ are the same, or at the respective midrange of manufacturers' recommendations, for the two test articles.

Specific fan power and external static pressure might still end up being quite different between test articles. The impact of such differences on the validity and credibility of final performance observations should be assessed at the outset of the project.

For credible results, one-time measurements of evaporator air flow rate, supply fan power, external static pressure, and total fan pressure should be made and sheave adjustments, if necessary, should also be made prior to final selection of a test pair. This is only possible/meaningful if multiple units of the advanced technology are already installed at time of selection. The more common situation is that of selecting an existing unit 1) to be replaced after it is monitored for a baseline period or 2) to be replaced at the outset with a second nearby existing unit to serve as the baseline.

The foregoing fan adjustment procedures require accurate traverses of air flows through the evaporator coils. The initial site visit needs to not only perform these one-time measurements (along with ESP, fan power, and fan RPM) but to establish the repeatability of traverses and, if possible, make the sheave adjustments or extract an agreement from site mechanics to make and document such adjustments.

Capacity Measurement. Air side measurements are problematic. Air flow, temperature (delta-T), humidity (delta-w) and barometric pressure must each be measured to sufficient accuracy that the resulting air flow can be established to, at worst, $5 \%$. (Our hope is that by using the same instruments, methods and installation conditions on both machines, the difference in measurement bias will be on the order of only 2 or $3 \%$. For example, the same barometer, used to establish ambient air pressure for both machines, is good to $1 / 2 \%$ and errors will affect both machines about equally.) With well-designed thermopiles and reasonably uniform face velocities we can measure the average temperature difference to within $1 \%$ $\left(\sim 0.1^{\circ} \mathrm{F}\right)$. Our problem is that the air flow and humidity difference measurements are difficult. Accuracies of $5 \%$ are difficult to achieve for either measurement and biases in the range of $10 \%$ would not be surprising in one or both. Humidity errors might be significantly reduced by using sampling tubes to average across the inlet and outlet faces of the coils. A further scheme to let the sensors alternate between sampling the upstream and downstream flows appears to be useful but has not, to our knowledge, ever been tried. 
The air flow measurement is also very difficult: package equipment simply does not present any good flow measuring locations. The best possibilities are at the downstream face of the coil and at the throat of the fan inlet. If repeatable and reconcilable measurements can be obtained at both locations, one may have some confidence of a 5\% number. This was not achieved for either unit at Ft. Gordon.

The alternative to air-side measurement is refrigerant-side measurement using refrigerant conditions at the evaporator inlet and outlet and either a compressor performance map (Appendix B; 5\% result) or a liquid line flowmeter ( $2 \%$ accuracy if $1 \%$ pressure, temperature and flow instruments are employed). The capacity is then given by the product of suction line volumetric flow rate, suction line density, and enthalpy change from the liquid line to the compressor suction port as described in Appendix A.

Conditions. The side-by-side protocol ensures that both units see the same conditions...or does it? The cooling loads presented to each unit are very sensitive to thermostat setpoint. We were fortunate to have a building manager willing to adjust and enforce thermostat setpoints for us. It was also fortunate that the zones communicate sufficiently to maintain a fairly uniform humidity.

The three requirements on indoor conditions are 1) that they be representative, 2) that they vary enough to produce data from which an EER model sensitive to evaporator entering-air conditions can be reliably inferred and 3) that they be nearly the same for both test articles. Much of the variation in entering air conditions is driven by variations in the outdoor air condition. It follows that the best situation for side-byside testing is one in which both zones have similar occupancies, operating schedules and internal gain densities and outdoor air fractions. These are important considerations in site selection. 


\section{References}

ANSI/ASHRAE 37-2005, Methods of Testing for Rating Electrically Driven Unitary Air-Conditioning and Heat Pump Equipment. http://webstore.ansi.org/ansidocstore

ARI, 2000. Standard for Performance Rating of Commercial and Industrial Unitary Air-Conditioning and Heat Pump Equipment (Standard 340/360) American Refrigeration Institute, Arlington, VA.

http://www.ari.org/std/standards.html

ASHRAE 1997. Handbook of Fundamentals, Chapter 28, Atlanta, GA.

Fuller, S.K. and A.S. Rushling, 2005. Energy Price Indices and Discount Factors for LCC AnalysisAnnual Supplement to NIST Handbook 135 and NBS Special Publication 709. NISTIR 85-3273-20 (Rev. 4/05). www.eere.energy.gov/femp/pdfs/ashb05.pdf

Hadley D.L. and P.R. Armstrong 2000. Energy Savings from Dual-Source Heat Pump Technology, DOE/EE-0220, U.S. Dept. of Energy Technology Installation Review, http://www.eere.energy.gov/femp/pdfs/heatpump.pdf

Hall, I., R. Prairie, H. Anderson and E. Boes, 1978. Generation of Typical Meteorological Years for 26 SOLMET Stations. SAND78-1601. Sandia National Laboratory, Albuquerque, NM.

Mairon, W. and K. Urban 1995. User's Manual for TMY2s Typical Meteorological Years. NREL, Golden, CO. http://rredc.nrel.gov/solar/pubs/tmy2/overview.html

Nemeth, Robert J., D. Fournier, L. Debaillie, et al., 1995. Department of Defense Renewables and Energy Efficient Planning (REEP) Program Manual, USACERL TR 95/20, August 1995, ADA 299345

Somasundaram, S., D.W. Winiarski and D.B. Belzer. 2002. "Screening Analysis for EPACT-Covered Commercial HVAC and Water-Heating Equipment", J. Energy Resources Technology, 124:116-124, Trans $A S M E$, New York, NY

Threlkeld, J.L., 1970. Thermal Environmental Engineering, ${ }^{\text {rd }}$ edtn., Prentice-Hall, Englewood Cliffs, NJ; see also Keuhn, T.H., et al, 1998, $3^{\text {rd }}$ edtn. 


\section{Distribution}

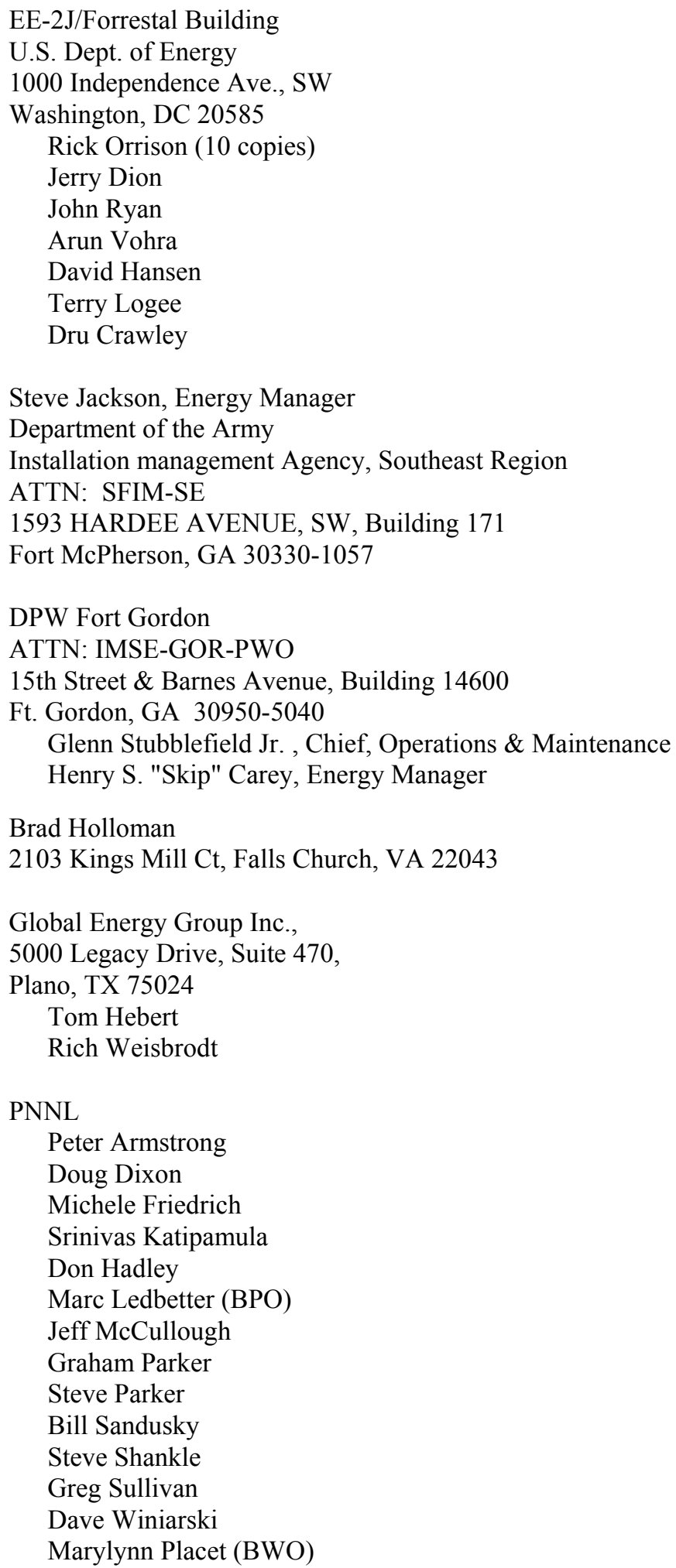

